\title{
What Antibiotic Exposures Are Required to Suppress the Emergence of Resistance for Gram-Negative Bacteria? A Systematic Review
}

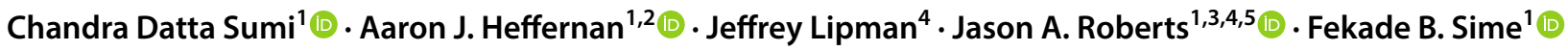

Published online: 20 July 2019

(c) Springer Nature Switzerland AG 2019

\begin{abstract}
Background The rates of antibiotic resistance in Gram-negative bacteria are increasing. One method to minimize resistance emergence may be optimization of antibiotic dosing regimens to achieve drug exposure that suppress the emergence of resistance.

Objective The aim of this systematic review was to describe the antibiotic exposures associated with suppression of the emergence of resistance for Gram-negative bacteria.

Methods We conducted a search of four electronic databases. Articles were included if the antibiotic exposure required to suppress the emergence of resistance in a Gram-negative bacterial isolate was described. Among studies, 57 preclinical studies (in vitro and in vivo) and 2 clinical studies 59 included investigated the monotherapy of antibiotics against susceptible and/or intermediate Gram-negative bacteria.

Results The pharmacokinetic/pharmacodynamic (PK/PD) indices reported to suppress the emergence of antibiotic resistance for various classes were $\beta$-lactam antibiotic minimum concentration to minimum inhibitory concentration $\left(C_{\min } / \mathrm{MIC}\right) \geq 4$; aminoglycoside maximum concentration to MIC $\left(C_{\max } / \mathrm{MIC}\right)$ ratio $\geq 20$; fluoroquinolones, area under the concentrationtime curve from 0 to $24 \mathrm{~h}$ to mutant prevention concentration $\left(\mathrm{AUC}_{24} / \mathrm{MPC}\right) \geq 35$; tetracyclines, $\mathrm{AUC}_{24}$ to $\mathrm{MIC}\left(\mathrm{AUC}_{24} /\right.$ MIC) ratio $\geq 50$; polymyxin $\mathrm{B}, \mathrm{AUC}_{24} / \mathrm{MIC} \geq 808$; and fosfomycin, $\mathrm{AUC}_{24} / \mathrm{MIC} \geq 3136$. However, the exposures required to suppress the emergence of resistance varied depending on the specific antibiotic tested, the duration of the experiment, the bacterial species and the specific bacterial isolate tested. Importantly, antibiotic exposures required to suppress the emergence of resistance generally exceeded that associated with clinical efficacy.
\end{abstract}

Conclusion The benefits of implementing such high PK/PD targets must be balanced with the potential risks of antibioticassociated toxicity.

Electronic supplementary material The online version of this article (https://doi.org/10.1007/s40262-019-00791-z) contains supplementary material, which is available to authorized users.

Jason A. Roberts

j.roberts2@uq.edu.au

1 Centre for Translational Anti-Infective Pharmacodynamics, School of Pharmacy, The University of Queensland, Brisbane, QLD, Australia

2 School of Medicine, Griffith University, Gold Coast, QLD, Australia

3 The University of Queensland Centre for Clinical Research (UQCCR), Faculty of Medicine, The University of Queensland, Brisbane, QLD, Australia

4 Department of Intensive Care Medicine, Royal Brisbane and Women's Hospital, Brisbane, QLD, Australia

5 Pharmacy Department, Royal Brisbane and Women's Hospital, Brisbane, QLD, Australia

\section{Key Points}

Generally, the antibiotic exposure for suppressing resistance emergence is higher than that associated with clinical efficacy.

The exposure required to suppress resistance emergence varies with bacterial species and specific isolates.

Resistance emergence may be more likely in the presence of a higher bacterial burden.

\section{Introduction}

The widespread use and misuse of antibiotics have led to the rapid emergence and global dissemination of antibiotic resistance $[1,2]$. Currently, up to $70 \%$ of Gram-negative 
bacteria may harbor extended-spectrum $\beta$-lactamase (ESBL) enzymes depending on geographical location, conferring resistance to commonly used antibiotics such as piperacillin/ tazobactam [3-5]. Commonly encountered multidrug-resistant bacteria may include carbapenem-resistant Acinetobacter baumannii, metallo- $\beta$-lactamase-producing Pseudomonas aeruginosa, and ESBL-producing Klebsiella pneumoniae, which are associated with increased morbidity and mortality in patients with a bacteraemia (odds ratio [OR] 2.98, 95\% confidence interval [CI] 2.36-3.75; $p<0.001$ ) [6].

Few new antibiotics and antibiotic combinations have been developed for the treatment of infections caused by resistant Gram-negative bacteria, such as plazomicin, ceftolozane/tazobactam, ceftazidime/avibactam, and meropenem/vaborbactam, however, resistance to these agents has been previously described $[7,8]$. Therefore, given the cost and time required for the development of new antibiotics, methods to minimize resistance emergence to both new and old antibiotics are of paramount importance $[9,10]$. One potential method is antibiotic dose optimization.

In vitro studies simulating current antibiotic dosing practices highlight that exposures associated with an increased probability of clinical cure may be insufficient to suppress the emergence of antibiotic-resistant Gram-negative bacteria $[11,12]$. Pharmacokinetic/pharmacodynamic (PK/ $\mathrm{PD})$ indices relate the antibiotic exposure to the antibiotic susceptibility of an infecting pathogen where susceptibility may be described as the minimum inhibitory concentration (MIC), thereby providing the clinician with a dosing target. In studies investigating the PK/PD targets required for clinical efficacy, common indices include the percentage of the dosing interval that the drug concentration exceeds the pathogen MIC $\left(\% T_{>\mathrm{MIC}}\right.$, e.g. $\beta$-lactam antibiotics), the maximum drug concentration to MIC ratio $\left(C_{\max } / \mathrm{MIC}\right.$, e.g. aminoglycosides) and the area under the drug concentration versus time curve (reflecting total antibiotic exposure) to MIC ratio (AUC/MIC, e.g. fluoroquinolones). Given that the MIC is a measure of susceptibility for the majority of the bacterial population at a standardized inoculum $\left(5.5 \times 10^{5}\right.$ colony-forming units per millilitre; $\mathrm{CFU} / \mathrm{mL}$ ), some studies have suggested that alternative measures of susceptibility reflecting the potential for resistance to develop may provide an advantage when determining the PK/PD targets required for suppressing resistance emergence. However, the inaccuracies in any MIC obtained by a single MIC test should also be considered due to assay variability [13]. One example is the mutant prevention concentration (MPC), which describes the antibiotic concentration required to suppress the growth of first-generation mutant bacteria that may selectively proliferate at concentrations above the MIC [14, 15]. The antibiotic concentration range between the MIC and the MPC is the mutant selection window (MSW). Antibiotic concentrations within the MSW promote the growth of resistant bacterial pathogens; thus, the antibiotic exposure required to suppress the emergence of resistance should be maintained above the MSW. Moreover, compared with MIC testing, MPC and MSW testing is conducted at higher bacterial burdens $>1 \times 10^{8} \mathrm{CFU} / \mathrm{mL}$, representing a serious bacterial infection that is more likely to facilitate resistance emergence than may be the case in common infection types $[13,16]$. Overall, no standardized definitions exist to determine the antibiotic exposures that should be targeted to suppress the emergence of antibiotic resistance against different bacterial burdens. Moreover, there remains a lack of research to define target antibiotic exposures needed to minimize the development of resistance. Thus, this systematic review aims to describe the currently known antibiotic PK/PD indices required to suppress the emergence of Gram-negative bacterial antibiotic resistance.

\section{Methods}

A systematic review of the literature was performed according to the guidelines of the Preferred Reporting Items for Systematic Reviews and Meta-Analyses (PRISMA) statement [17].

\subsection{Search Strategy}

Four electronic databases (PubMed, EMBASE, SCOPUS, and Web of Science) were searched for studies, published between January 1953 and March 2019, investigating antibiotic exposures required to suppress the emergence of antibiotic resistance in Gram-negative bacteria. We designed the search strategy based on four concept areas as follows:

1. 'Anti-bacterial agents' (MeSH) OR 'anti-infective agents' (MeSH)) OR 'beta-lactams' (MeSH) OR 'penicillins' (MeSH) OR antibacter* OR anti-bacter* OR antimicrobial* OR anti-microbial OR antibiotic* OR anti-biotic* OR beta-lactam* OR penicillin* OR ampicillin OR piperacillin* OR cephalosporin* OR carbapenem* OR imipenem OR meropenem OR doripenem OR ertapenem OR cefepime OR polymyxin* OR colistin OR colisti* OR tobramicin OR tobramycin OR aminoglycoside* OR ceftaroline OR ciprofloxacin OR fosfomycin OR phosphonomycin* OR amikacin OR aztreonam OR gentamicin OR gentamycin OR levofloxacin OR ceftozolane OR moxifloxacin OR tigecycline OR minocycline OR glycylglycine OR tetracycline OR chloramphenicol OR rifampicin OR kanamycin.

2. Resistance OR multi-drug resistance OR drug resistance OR antibiotic resistance OR antimicrobial resistance. 
3. Dose OR concentration OR exposure OR pharmacokinetic*.

4. Mutant prevention concentration OR mutant selection window OR suppress OR suppression OR pharmacodynamic*.

Each search was limited to English-language articles only. Finally, the searches (1), (2), (3) and (4) were combined with 'AND' as a Boolean Operator. In addition, the reference lists of included studies were searched manually to identify additional records.

\subsection{Inclusion and Exclusion Criteria}

Exposure for suppression of antibiotic resistance emergence was defined as an exposure that prevents the growth of the test bacteria on antibiotic-containing agar, or an increase in the MIC of the culture. This includes the complete eradication of the bacterial culture within the defined time frame of the experiment.

Inclusion criteria were as follows:

(a) Antibiotic: Currently clinically used for the treatment of infections in humans.

(b) Microorganism: Gram-negative bacteria.

(c) Type of therapy and duration of exposure: Monotherapy over any duration of exposure.

(d) Study model: In vitro pharmacodynamic model simulating human pharmacokinetics and/or in vivo animal model, or clinical study.

(e) Outcome: Antibiotic exposure and/or the PK/PD ratio required for the emergence of resistance suppression against previously susceptible and/or intermediate (according to the European Committee on Antimicrobial Susceptibility Testing [EUCAST] or Clinical and Laboratory Standards Institute [CLSI] definitions) Gram-negative bacteria.

Exclusion criteria were as follows:

(a) Review articles (systematic and narrative) and metaanalyses.

(b) Studies describing the pharmacodynamics of combination therapy with two or more antibiotics.

(c) Studies describing the emergence of antibiotic resistance in an in vivo microbiota that was distinct from the original experimental infection site.

\subsection{Selection of Studies and Data Extraction}

The reference management software EndNote X8 (Clarivate Analytics, Philadelphia, PA, USA) was used to manage all data retrieved from the four electronic databases.
Two reviewers (CDS and AJH) independently screened all studies by title and abstract for full-text review. Both reviewers resolved any disagreement through consensus, or, if necessary, in consultation with a third reviewer (FBS). Relevant characteristics extracted from the full-text studies were study type (in vitro, in vivo, clinical study), antibiotic tested, bacterial isolate, experimental apparatus, simulated human pharmacokinetic profile (clearance [CL], drug exposures and/or dosing regimens, and elimination half-life $\left.\left[t_{1 / 2}\right]\right)$, baseline bacterial burden, method(s) for determination of the resistant subpopulation, and study outcomes in terms of the required drug exposures and PK/PD indices for suppression of emergence of resistance. Details of the protocol for this systematic review were registered on PROSPERO (ID: CRD42018098631).

\subsection{Quality Assessment}

Both reviewers independently assessed the methodological quality of the included studies and assessed their appropriateness for inclusion in this review. A list of methodological items was developed for quality assessment of the included preclinical (in vitro and in vivo) studies, described in a previous study [18] (Table 1). This list included a total of 11 items to assess a study's methodological quality, such as the aim of study, microorganism characterization, antibacterial agents, bacterial concentration, pharmacokinetic data, type of pharmacodynamic model used for the study, study observation period, control group, antibiotic concentration determination assay, resistant subpopulation selection, and outcomes. Moreover, there were a total of 17 sub-items and each sub-item was reported as 0 (not described) or 1 (described).

\subsection{Outcomes and Data Analysis}

The included studies were grouped into two categories based on study type: preclinical (in vitro and in vivo) or clinical studies. The outcomes of interest were used to identify the drug exposures and/or the PK/PD indices required to suppress the emergence of resistance. Suppression of emergence of resistance was defined as the presence of a bacterial population without an MIC shift and/or a bacterial burden below the lower limit of quantification (LLQ) on antibioticimpregnated agar plates at any concentration over the duration of the experiment.

\section{Results}

Our search strategy identified 10,311 studies, of which 215 were selected for full-text review. Of those 215 studies, 156 were excluded, resulting in 59 studies being included in our 
Table 1 Methodological items for quality assessment of the preclinical (in vitro and in vivo) studies

\begin{tabular}{|c|c|c|}
\hline Items & Sub-items & Score $^{\mathrm{a}}$ \\
\hline Aim of the study & i. The question addressed in the study is clearly stated & 0 or 1 \\
\hline \multirow[t]{4}{*}{ Microorganism characterization } & ii. Name of strain(s) & 0 or 1 \\
\hline & iii. Type of strain(s), e.g. wild-type, clinical isolate, laboratory isolate(s) & 0 or 1 \\
\hline & iv. Number of test strains & 0 or 1 \\
\hline & v. Baseline MIC of the strain & 0 or 1 \\
\hline Antibacterial agents & vi. Name of test antibacterial agent(s) & 0 or 1 \\
\hline Bacterial concentration & vii. Baseline bacterial concentration used & 0 or 1 \\
\hline \multirow[t]{3}{*}{ Pharmacokinetic data } & viii. Elimination half-life $\left(t_{1 / 2}\right)$ & 0 or 1 \\
\hline & ix. Drug exposure and/or dosing regimen & 0 or 1 \\
\hline & x. Mode of administration & 0 or 1 \\
\hline Type of pharmacodynamic model used for the study & $\begin{array}{l}\text { xi. One-/two-compartment model (in vitro studies) or animal model (in vivo stud- } \\
\text { ies) }\end{array}$ & 0 or 1 \\
\hline Study observation period & xii. Duration of study observation & 0 or 1 \\
\hline Control group & xiii. Control group(s) without any antibiotic treatment used & 0 or 1 \\
\hline Antibiotic concentration determination assay & xiv. Drug concentration measurement method & 0 or 1 \\
\hline Resistant subpopulation selection & $\begin{array}{l}\text { xv. Method(s) for resistant subpopulation selection: Resistant subpopulation may } \\
\text { be identified by drug-supplemented media plates (with concentration drug speci- } \\
\text { fied) AND/OR at least one MIC performed per guidelines following antibiotic } \\
\text { exposure }\end{array}$ & 0 or 1 \\
\hline \multirow[t]{2}{*}{ Outcomes } & xvi. Drug exposure(s) for suppression of emergence of resistant & 0 or 1 \\
\hline & $\begin{array}{l}\text { xvii. Analysis of PK/PD indices for suppression of emergence of resistance: e.g. } \\
\text { AUC/MIC, } C_{\max } / \mathrm{MIC}, T_{>\mathrm{MIC}} \text {, or any new PK/PD indices described by the study } \\
\text { for suppression of emergence of resistance }\end{array}$ & 0 or 1 \\
\hline
\end{tabular}

$A U C$ area under the concentration-time curve, $C_{\max }$ maximum concentration, $M I C$ minimum inhibitory concentration, $P K / P D$, pharmacokinetic/ pharmacodynamic, $A U C / M I C$ ratio of AUC and MIC, $C_{m a x}$ MIC ratio of $C_{\max }$ and MIC, $T_{>M I C}$ concentration of antibiotic times above the MIC

${ }^{\mathrm{a}}$ The sub-items are scored as follows: 0 , not reported; or 1 , reported

systematic review. The complete search strategy and study selection process are presented in Fig. 1.

\subsection{Study Characteristics}

A summary description of the study characteristics and outcome measurements of the included preclinical in vitro 10659 studies is reported in Table 2 . The 46 in vitro studies reported on exposures of $\beta$-lactams, carbapenems, fluoroquinolones, aminoglycosides, polymyxins, fosfomycin, tetracycline and glycylcyclines for suppression of emergence of resistance. Most in vitro studies $(n=30)$ used a two-compartment pharmacodynamic model as opposed to a one-compartment pharmacodynamic model $(n=15)$ to assess the antibiotic exposures against test Gram-negative bacteria. Only Alou et al. [31] used a multiple-compartment bladder infection model for their study. With the exception of that study, all studies had a study duration of at least $24 \mathrm{~h}$. In Table 3, a summary of characteristics of the 11 included preclinical in vivo studies is presented. Most of the in vivo studies $(n=6)$ reported on $\beta$-lactam exposures for suppression of emergence of resistance. All in vivo studies were observed for at least for $24 \mathrm{~h}$. Finally, the characteristics of the included clinical studies are summarized in Table 4. These clinical studies reported PK/ PD indices for resistance suppression [76, 77]; however, the bacterial concentration at the site of infection was not determined in those studies.

\subsection{Quality of Studies}

As shown in electronic supplementary Table S1, among the preclinical in vitro studies, the quality assessment score range was 14-17, mode 16. Among 46 in vitro studies, 9 reported all the methodological quality assessment items. The studies that scored more than 14 provided information regarding the simulated pharmacokinetic profile. In the case of 11 preclinical in vivo studies, the range of quality assessment scores was 14-16, mode 15 (electronic supplementary Table S2). The total quality score data followed a skewed distribution, and the number of studies was not comparable between the in vitro and in vivo study groups. Quality assessment was not performed for the two clinical studies available for this review. 
Fig. 1 Systematic literature search and selection process in accordance with the PRISMA guidelines. PRISMA Preferred Reporting Items for Systematic Reviews and Meta-Analyses
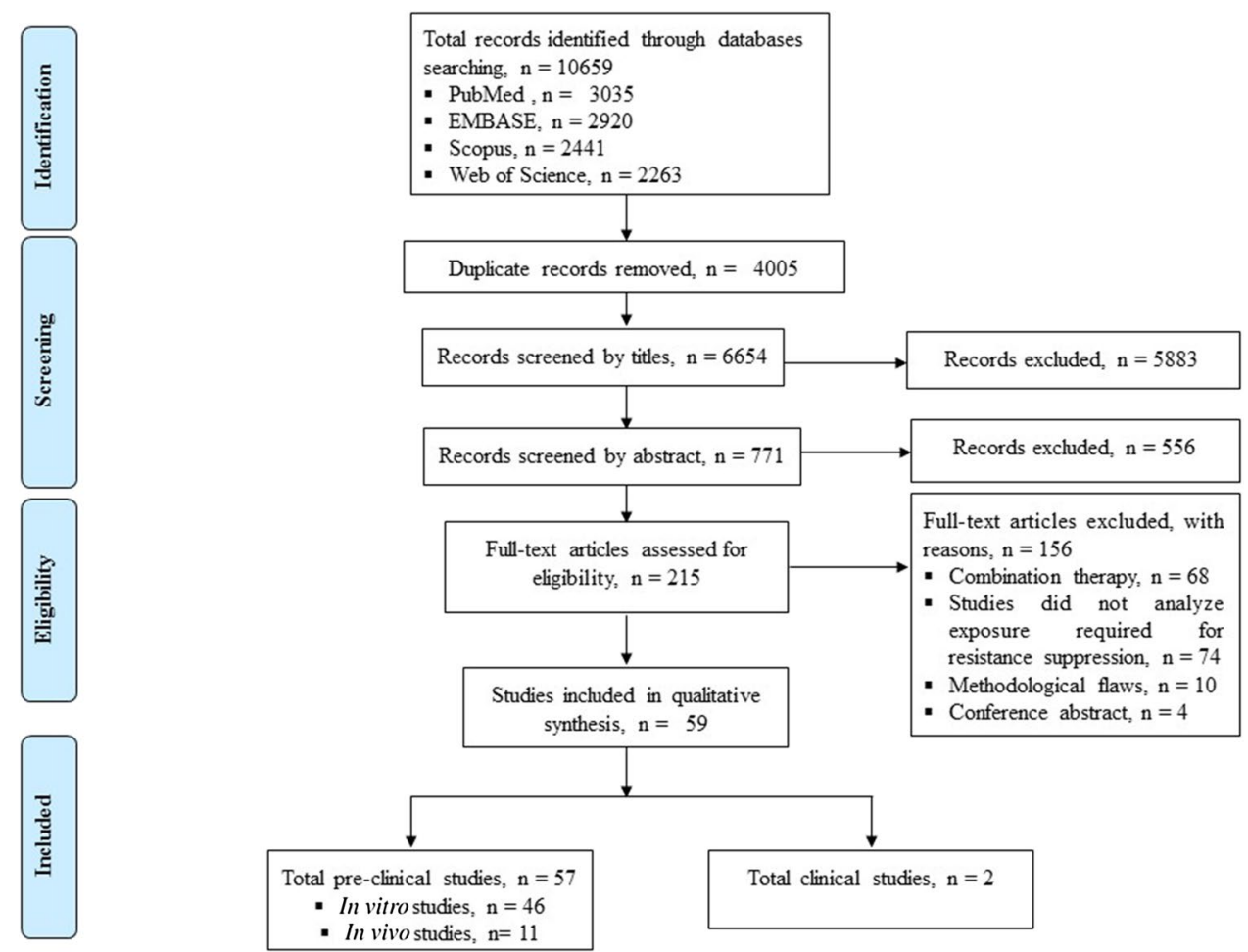

\subsection{Study Outcomes}

\subsection{1 $\beta$-Lactams}

As shown in Table 5, total and unbound $T_{>\text {MIC }}$ was the relevant PK/PD index describing the suppression of emergence of $\beta$-lactam antibiotic resistance in most included studies. Studies that were conducted for up to $72 \mathrm{~h}$ using a bacterial burden of $1 \times 10^{6} \mathrm{CFU} / \mathrm{mL}$ demonstrated that $100 \% T_{>\text {MIC }}$ was sufficient to suppress the emergence of bacterial resistance for penicillins and cephalosporins. No in vitro study involving carbapenems was conducted for $<120 \mathrm{~h}$. Studies that observed the emergence of resistance for a duration $>120 \mathrm{~h}$ suggest that for all $\beta$-lactam antibiotics, higher exposure with a minimum concentration $\left(C_{\min }\right) / \mathrm{MIC}$ ratio ranging from 1 to $\sim 8$ may be required to suppress resistance. Importantly, studies with a duration $>120 \mathrm{~h}$ also used a higher bacterial burden of $>1 \times 10^{7} \mathrm{CFU} / \mathrm{mL}$ compared with studies conducted for $<120 \mathrm{~h}$ that used a bacterial burden of $\sim 1 \times 10^{6} \mathrm{CFU} / \mathrm{mL}$. Only the study of a dynamic hollowfibre infection model (HFIM) conducted by Felton et al. [40] directly compared the PK/PD indices required to suppress the emergence of bacterial resistance over the same time period for a high $\left(\sim 8 \times 10^{8} \mathrm{CFU} / \mathrm{mL}\right)$ and low $\left(1 \times 10^{6} \mathrm{CFU} /\right.$ $\mathrm{mL}$ ) initial bacterial burden (Pseudomonas aeruginosa). The exposure required to suppress the emergence of resistance for piperacillin/tazobactam administered as a bolus was a $C_{\min }$ /MIC of 3.4, compared with 4.6 against the high bacterial burden. When a $3 \mathrm{~h}$ prolonged infusion of piperacillin/ tazobactam was employed, the $C_{\min }$ /MIC required to suppress the emergence of resistance was 10.4 and 11.9 for the low and high bacterial inoculum, respectively. However, against the low inoculum, achieving a piperacillin/tazobactam exposure of a $C_{\min } / \mathrm{MIC}$ of 3.4 or 10.4 , for the bolus and prolonged infusion, respectively, reduced the bacterial burden to below the LLQ over the study duration. In contrast, there was no significant bacterial killing against the high $P$. aeruginosa inoculum over the study duration [40].

Only one study has combined data for different $\beta$-lactam antibiotics (ceftazidime, cefepime and meropenem) to determine the exposure required for the suppression of emergence resistance for two K. pneumoniae and two $P$. aeruginosa isolates [58]. Classification and regression-tree analysis showed a $\beta$-lactam antibiotic $C_{\min } / \mathrm{MIC} \geq 3.8$ is required to suppress the emergence of resistance against most isolates tested. Further evidence of a difference in the exposure required to suppress the emergence of resistance between bacterial species is demonstrated in experiments with ceftolozane/tazobactam. The approximate human dosing regimen of ceftolozane/ tazobactam required to suppress the emergence of resistance for three Escherichia coli isolates (CTX-M-15, MIC $0.25 \mathrm{mg} / \mathrm{L}$; CMY-10, MIC $1 \mathrm{mg} / \mathrm{L}$; and a wild-type isolate, MIC $0.25 \mathrm{mg} / \mathrm{L}$ ) and two $P$. aeruginosa isolates (a wild-type, MIC $0.5 \mathrm{mg} / \mathrm{L}$; and a MexA/MexB efflux pump overexpressing isolate; MIC $4 \mathrm{mg} / \mathrm{L}$ ) was $\geq 1 / 0.5 \mathrm{~g}$ and $\geq 2 / 1 \mathrm{~g}$ administered every $8 \mathrm{~h}$ as a $1 \mathrm{~h}$ infusion, respectively [42, 45]. In addition to the bacterial species, inoculum and MIC, specific bacterial phenotypes may influence the threshold required to 


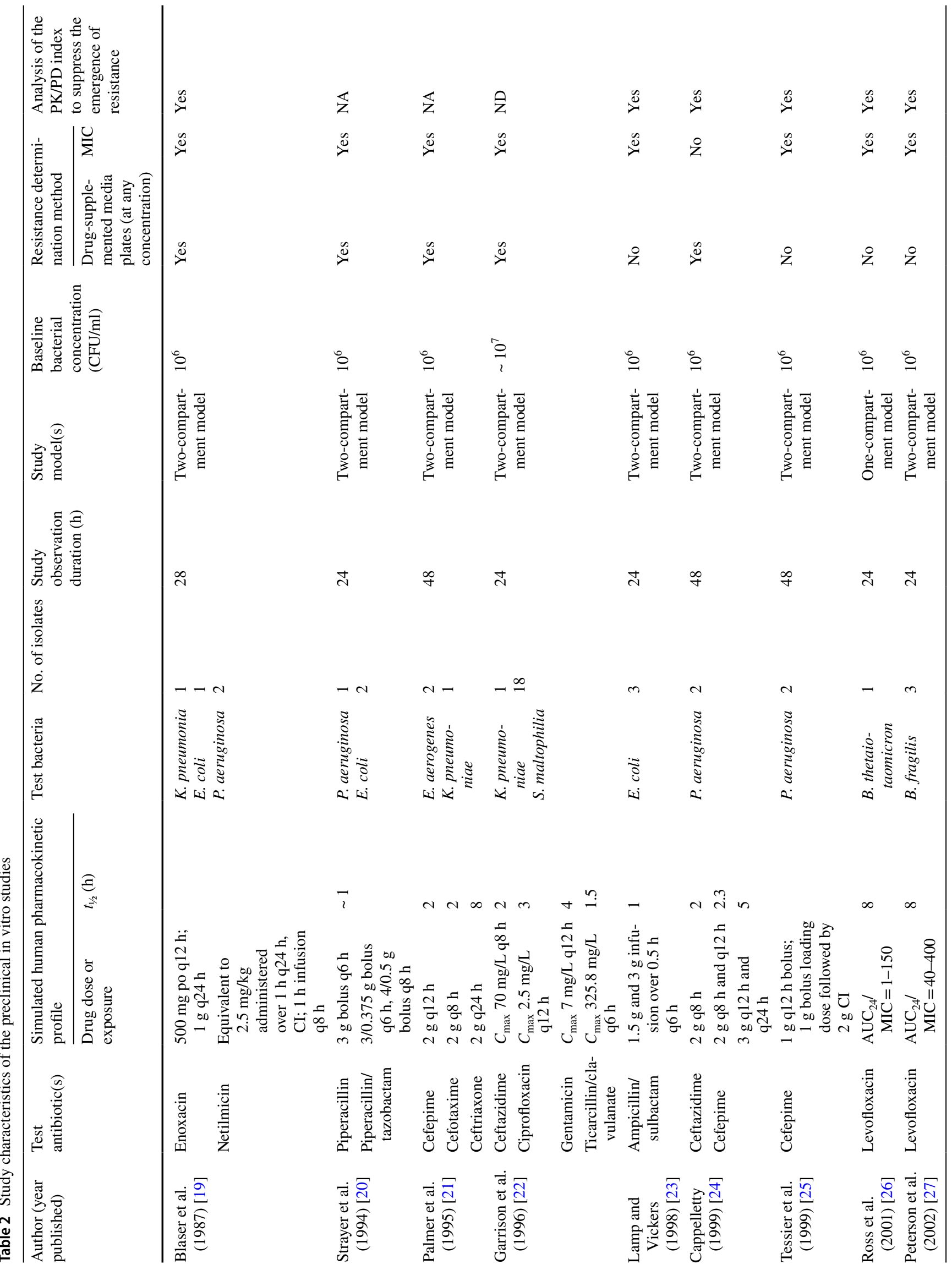




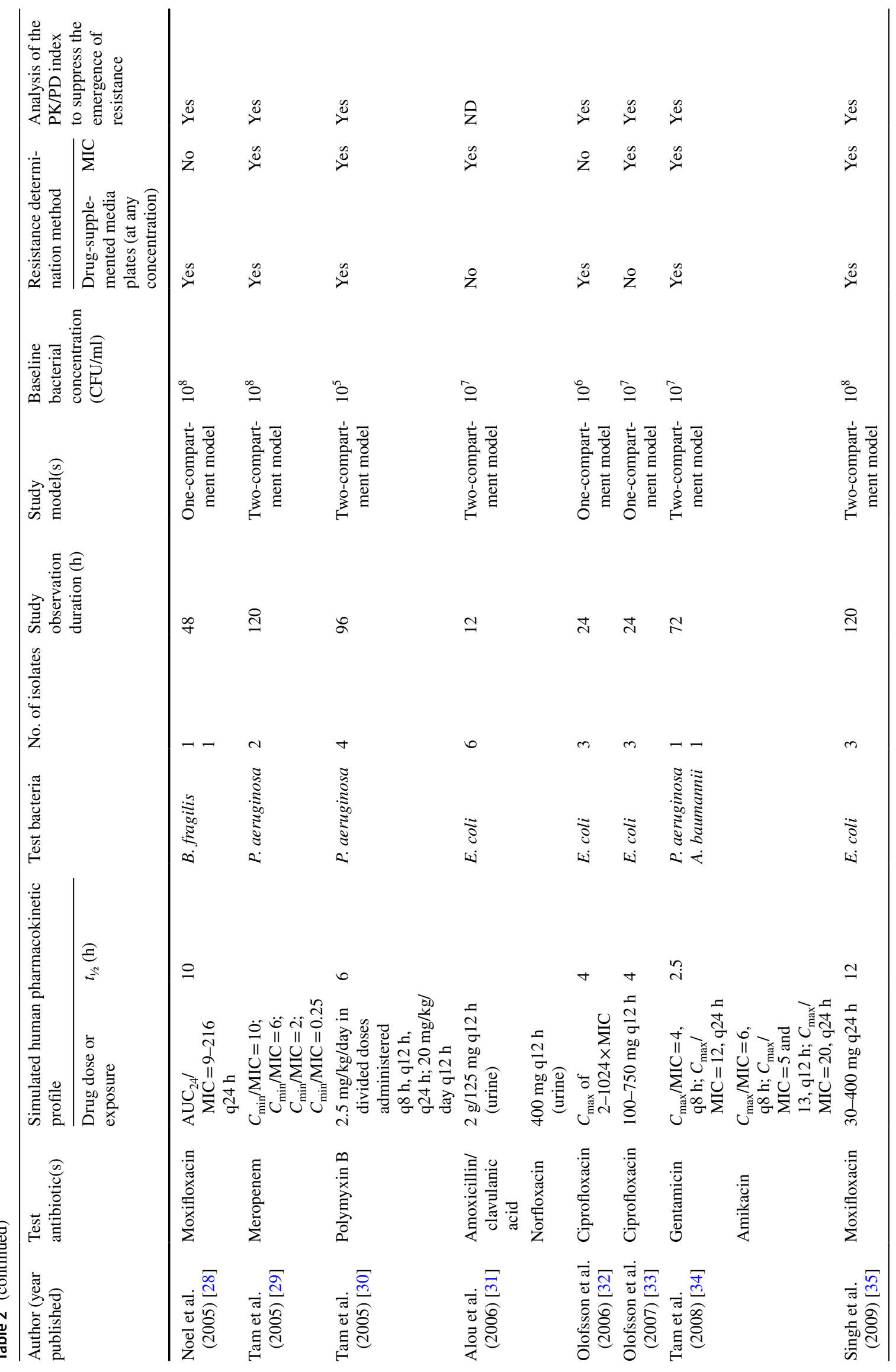




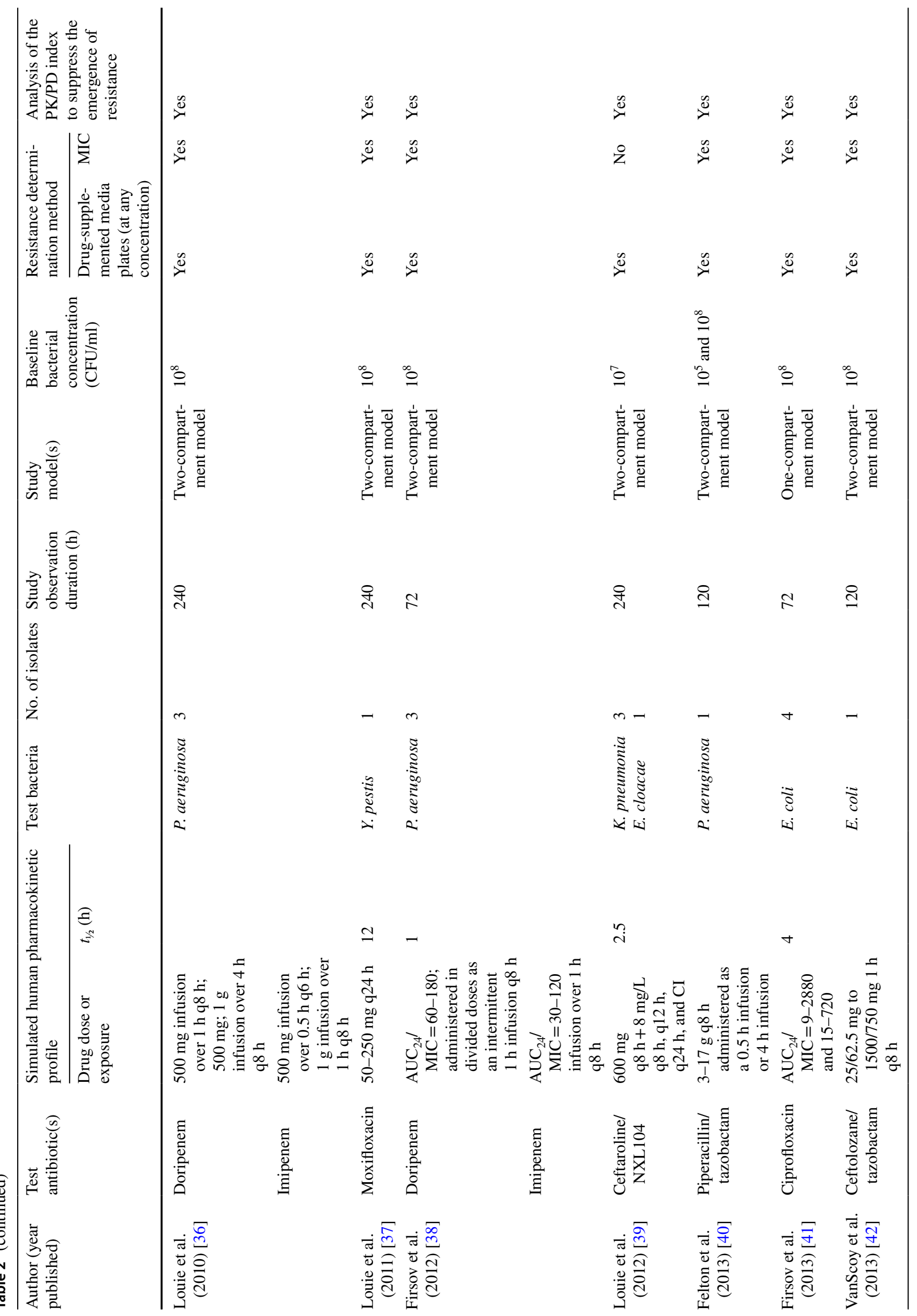




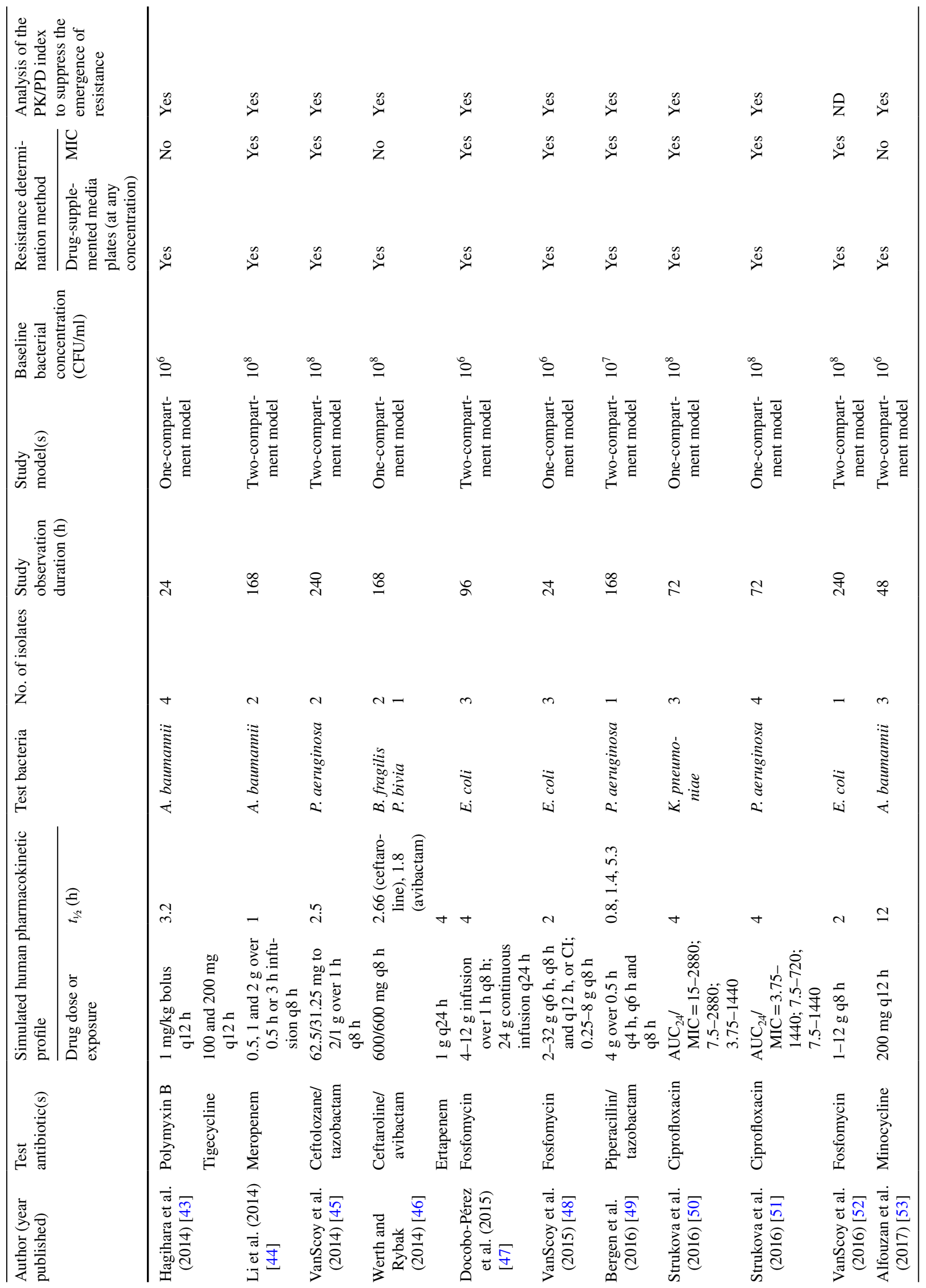




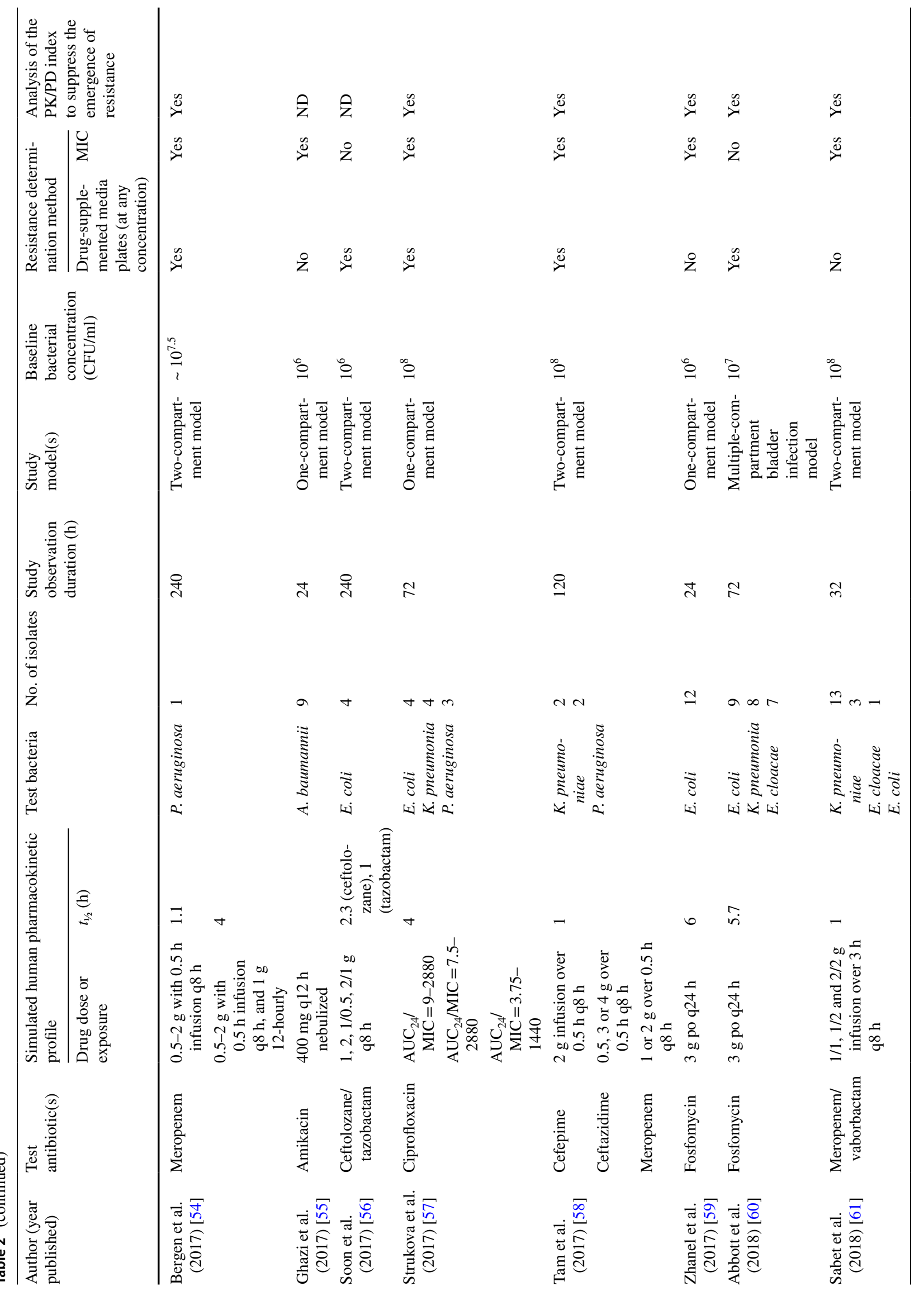




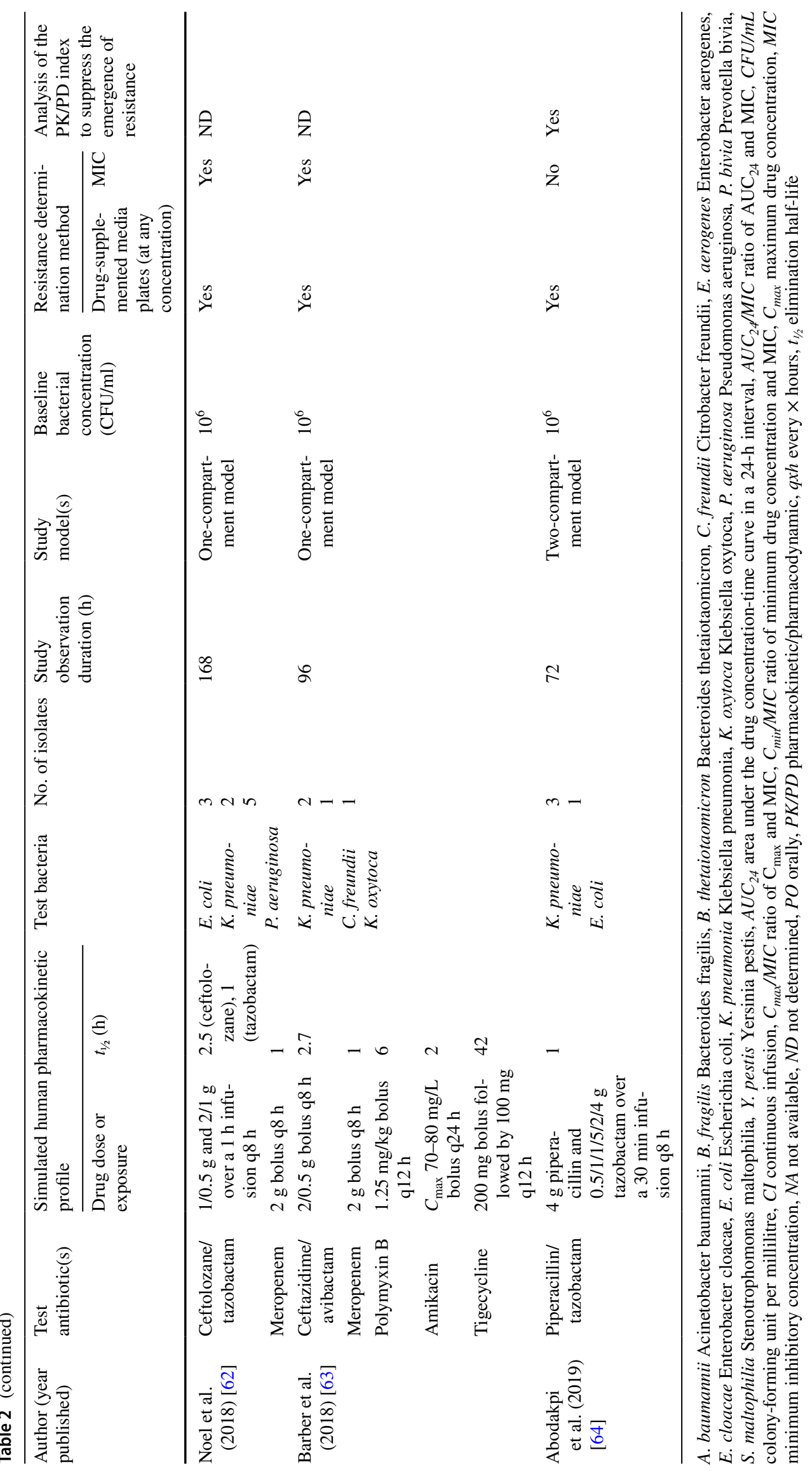




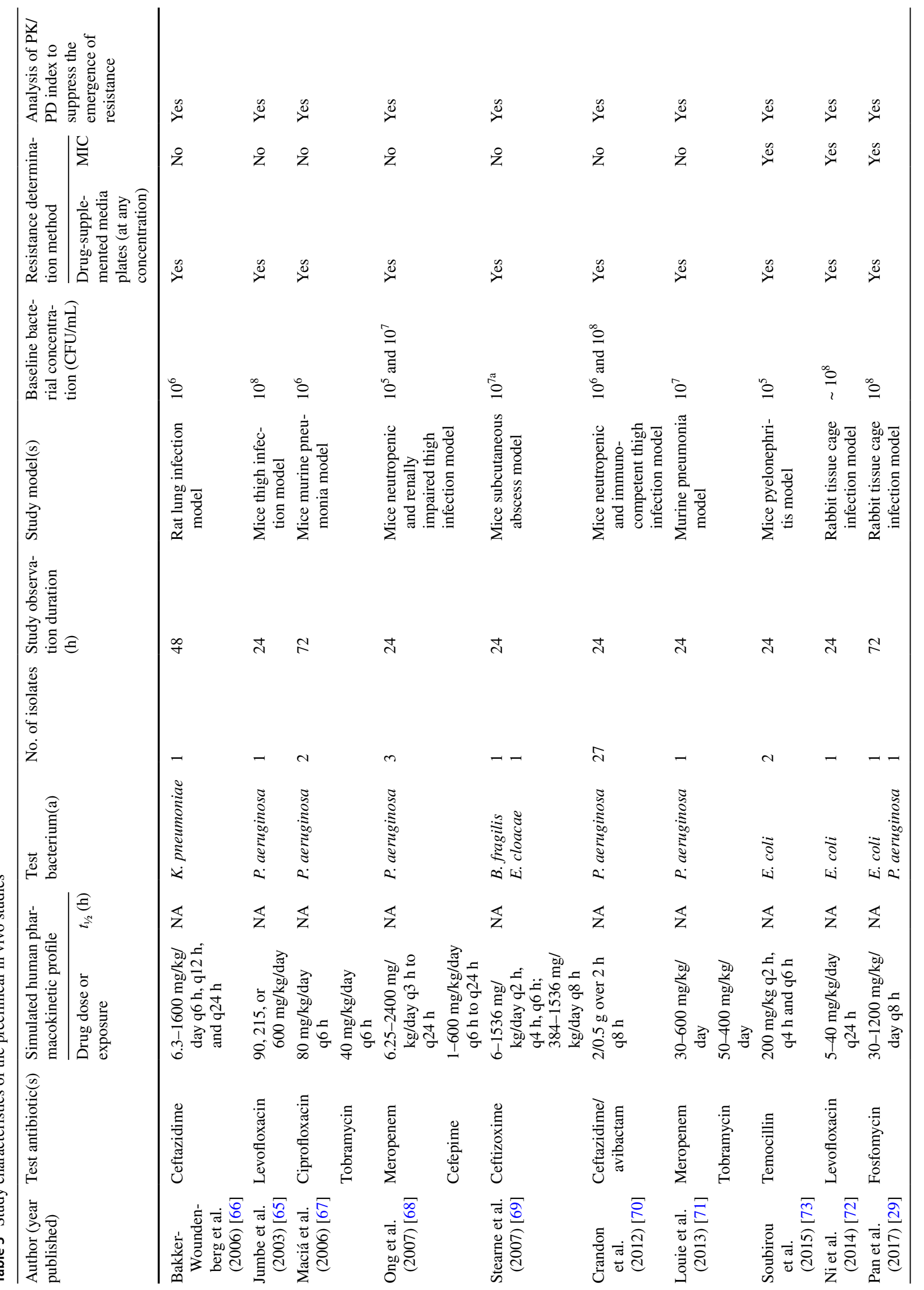




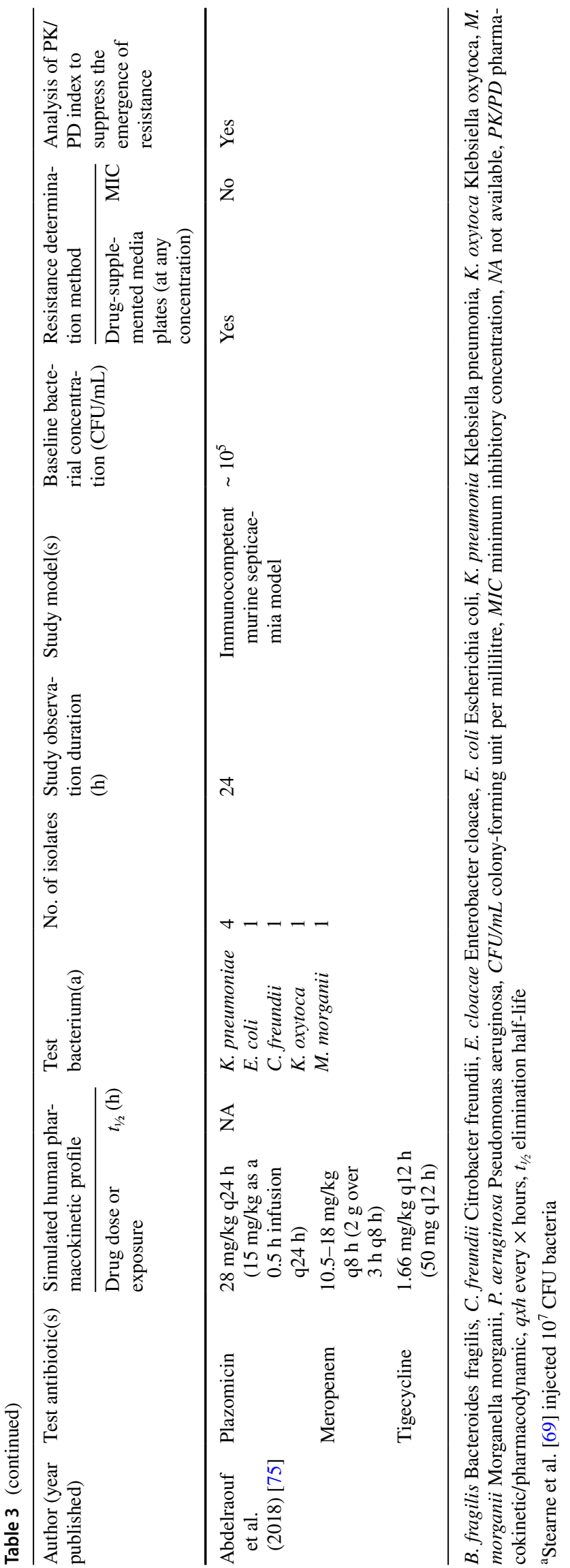

suppress the emergence of resistance. An in vitro study in a two-compartment pharmacodynamic model by Cappelletty [24] compared mucoid and non-mucoid $P$. aeruginosa (both MIC $8 \mathrm{mg} / \mathrm{L}$ ). Against the non-mucoid isolate, a cefepime exposure of $85 \% \mathrm{~T}_{>\mathrm{MIC}}$ suppressed the emergence of resistance. In contrast, the same exposure could not suppress the emergence of resistance against the mucoidal isolate.

The results of the in vivo studies are similar to the results of the in vitro studies conducted over $24 \mathrm{~h}$. Meropenem and imipenem exposures of $40 \% T_{>\text {MIC }}$ were reported to suppress the emergence of antibiotic resistance against three susceptible $P$. aeruginosa isolates (meropenem MICs $0.125,0.25$ and $1 \mathrm{mg} / \mathrm{L}$; imipenem MICs 1,1 and $1 \mathrm{mg} / \mathrm{L}$ ) in a neutropenic murine model over $24 \mathrm{~h}$ (Table 6) [68]. In contrast, the exposures required to suppress the emergence of resistance in vitro for meropenem in studies conducted over $>120 \mathrm{~h}$ were a $C_{\min } / \mathrm{MIC}$ of between 2 and $6[54,58]$.

\subsubsection{Aminoglycosides}

The relevant $\mathrm{PK} / \mathrm{PD}$ ratio describing the suppression of emergence of aminoglycoside resistance is the $C_{\max } /$ MIC ratio (Table 5). Achieving a netilmicin $C_{\max } / \mathrm{MIC}$ ratio of $\geq 8 \mathrm{mg} / \mathrm{L}$ suppressed the emergence of resistance in vitro, in the dynamic HFIM against $E$. coli (MIC $1 \mathrm{mg} / \mathrm{L}$ ), $K$. pneumoniae (MIC $0.125 \mathrm{mg} / \mathrm{L}$ ) and $P$. aeruginosa $(\mathrm{MIC} \leq 8 \mathrm{mg} / \mathrm{L})$.

Using the dynamic in vitro HFIM model, Tam et al. [34] demonstrated that an amikacin $C_{\max } / \mathrm{MIC}$ of 13 or a $C_{\max } /$ MIC of 20 was required to suppress the emergence of resistance when administered twice or once daily, respectively, against $A$. baumannii (MIC $2 \mathrm{mg} / \mathrm{L}$ ) over $72 \mathrm{~h}$. Similarly, Ghazi et al. [55] reported that a simulated exposure following $400 \mathrm{mg}$ of nebulized amikacin administered twice daily in an in vitro dynamic one-compartment model prevented the regrowth of resistant subpopulation of a clinical isolate of A. baumannii (MIC $2 \mathrm{mg} / \mathrm{L}$ ).

For gentamicin, a $C_{\max } / \mathrm{MIC}$ ratio of 30 when administered twice daily was reported to suppress the resistance emergence of $P$. aeruginosa (MIC $2 \mathrm{mg} / \mathrm{L}$ ); however, even a $C_{\max } / \mathrm{MIC}$ ratio $>36$ when administered as a single-daily dose was unable to suppress the emergence of resistance [34]. The PK/PD indices identified in vitro were similar to those found in a mouse lung infection model study by Maciá et al. [67], who demonstrated that a plasma tobramycin $C_{\max }$ I MIC ratio of 19 when administered four times daily prevented the emergence of resistance against a wild-type $P$. aeruginosa (MIC $1 \mathrm{mg} / \mathrm{L}$ ) in a murine pneumonia infection model (Table 6). In a separate murine pneumonia model, Louie et al. [71] reported that an $\mathrm{AUC}_{24} / \mathrm{MIC}$ ratio $\geq 110.6$ in the epithelial lining fluid of the lungs was required to suppress the resistance emergence of wild-type $P$. aeruginosa (MIC $1 \mathrm{mg} / \mathrm{L}$ ). 


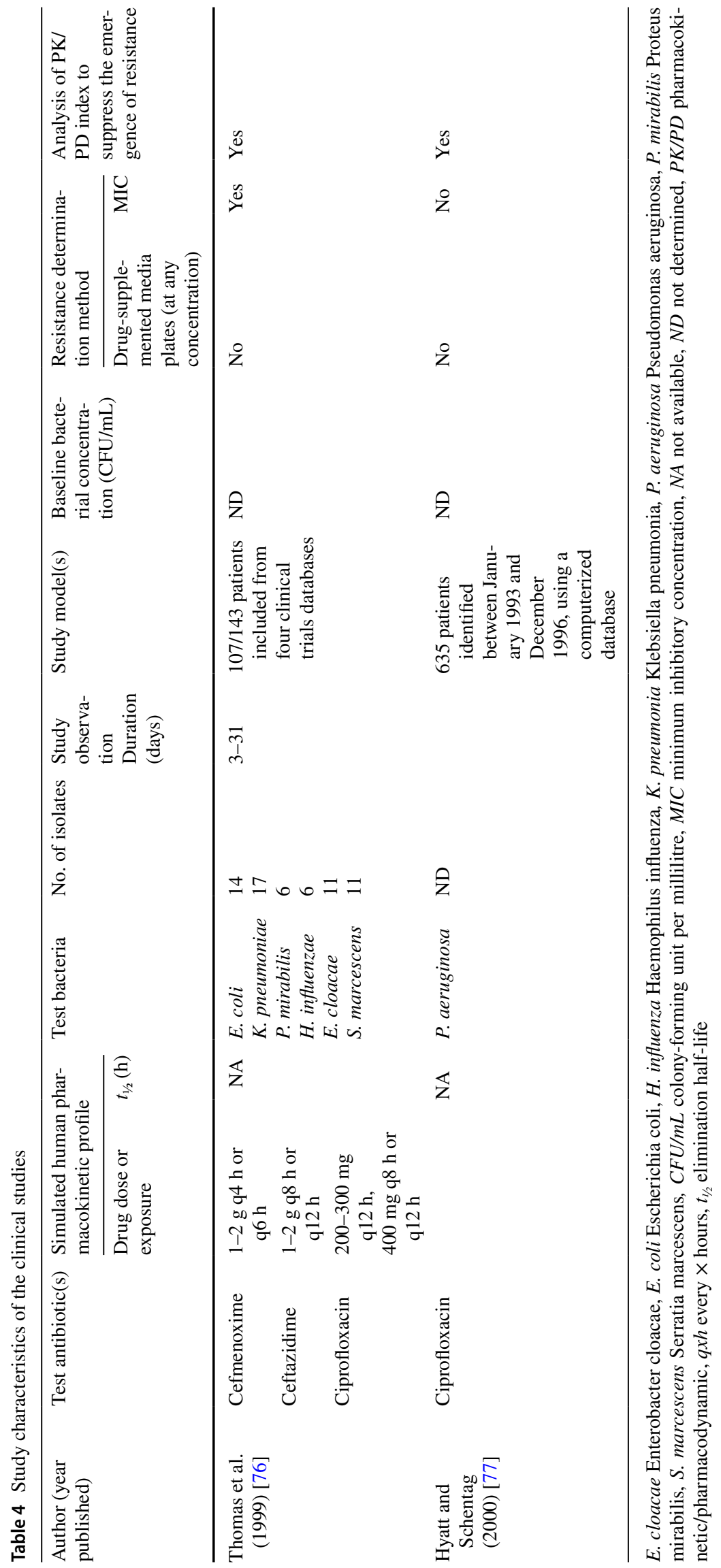




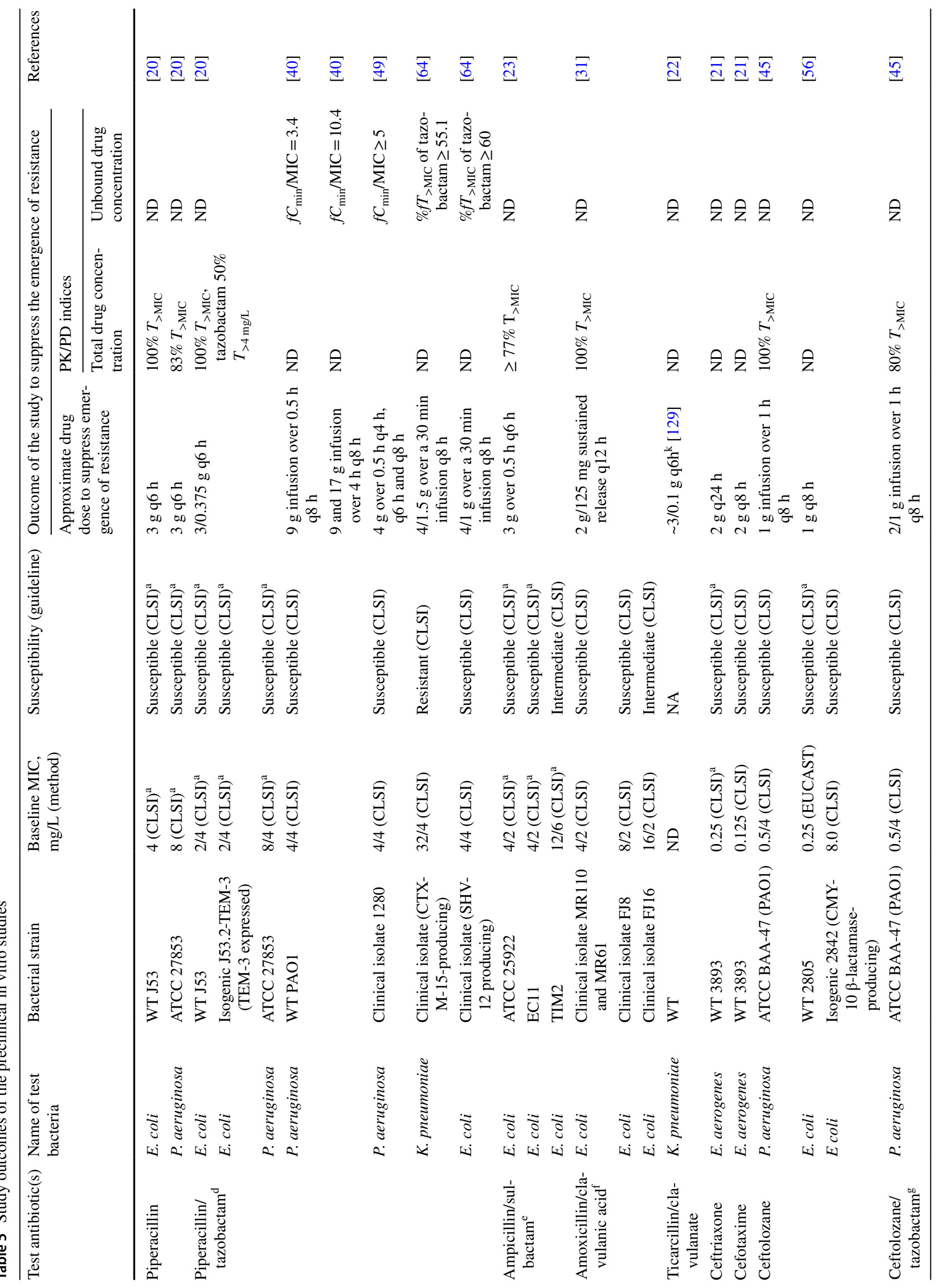




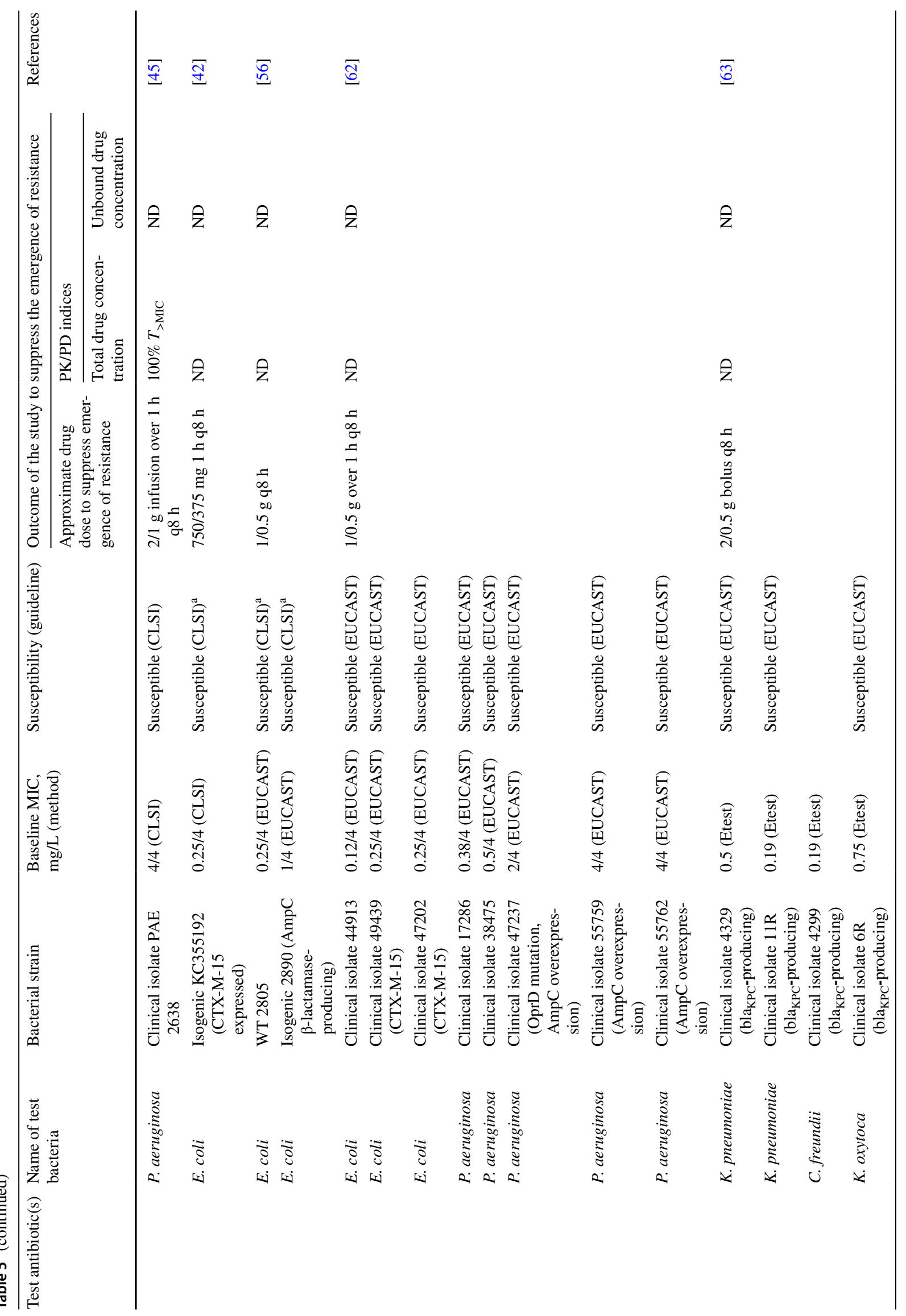




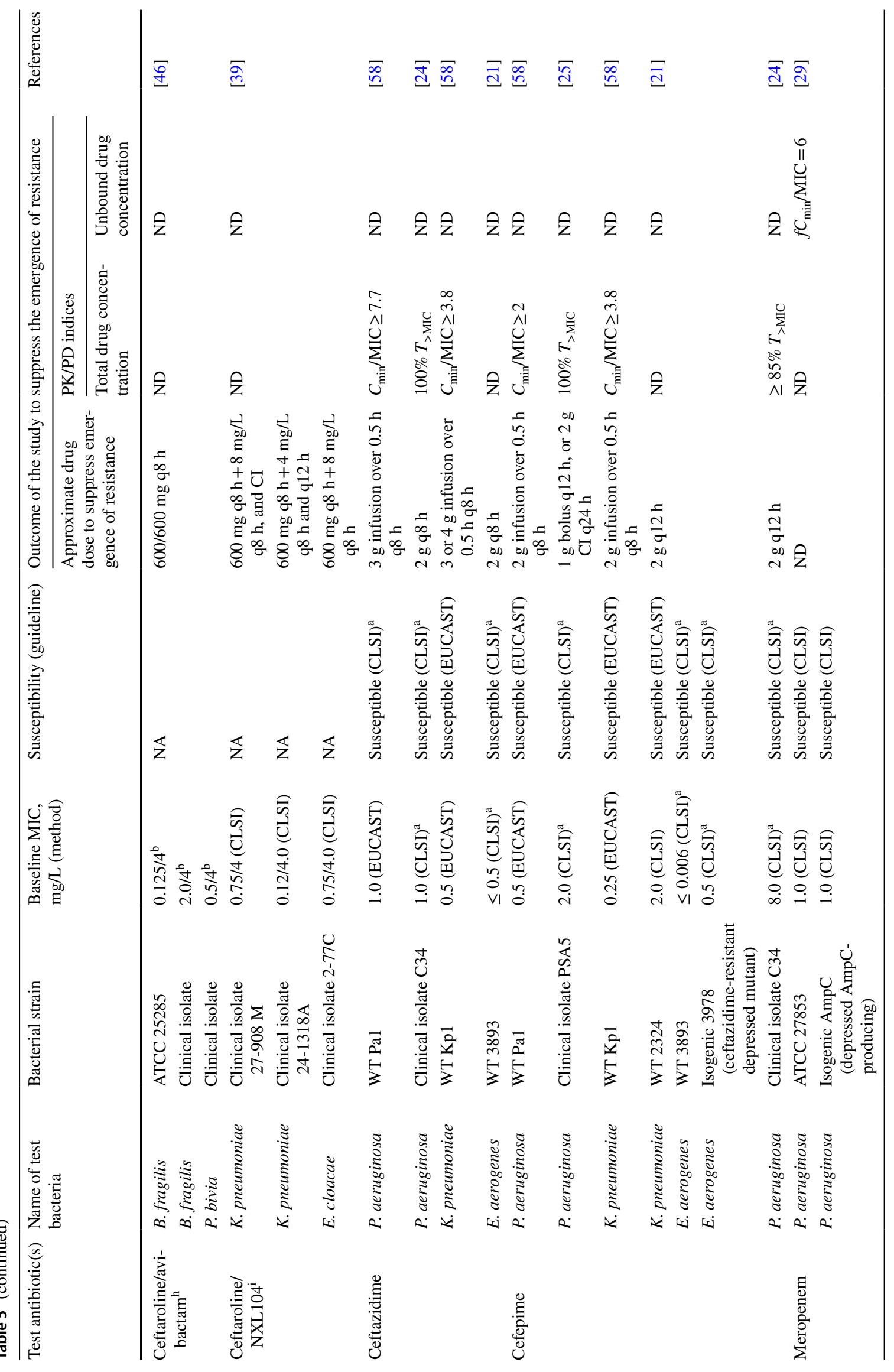




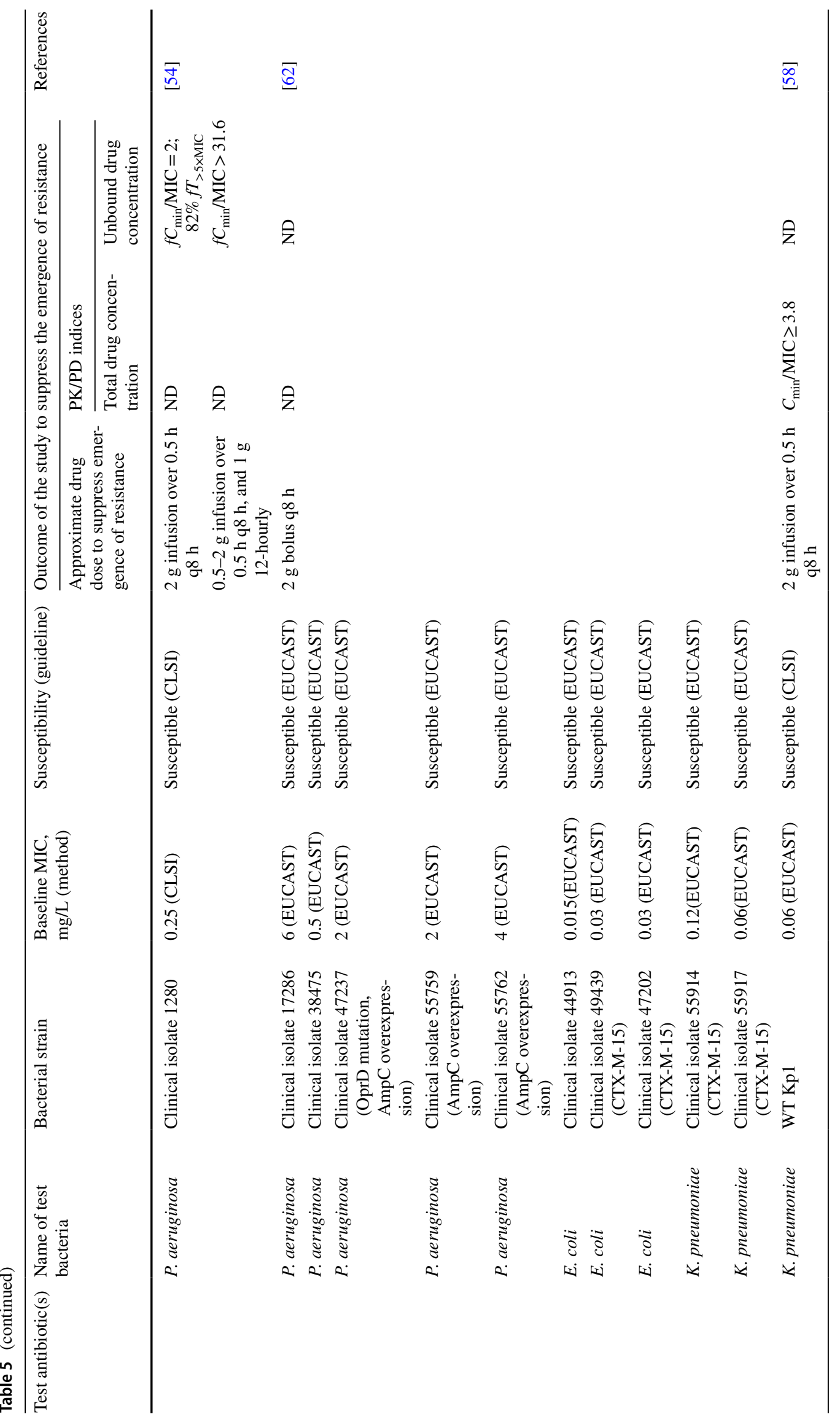




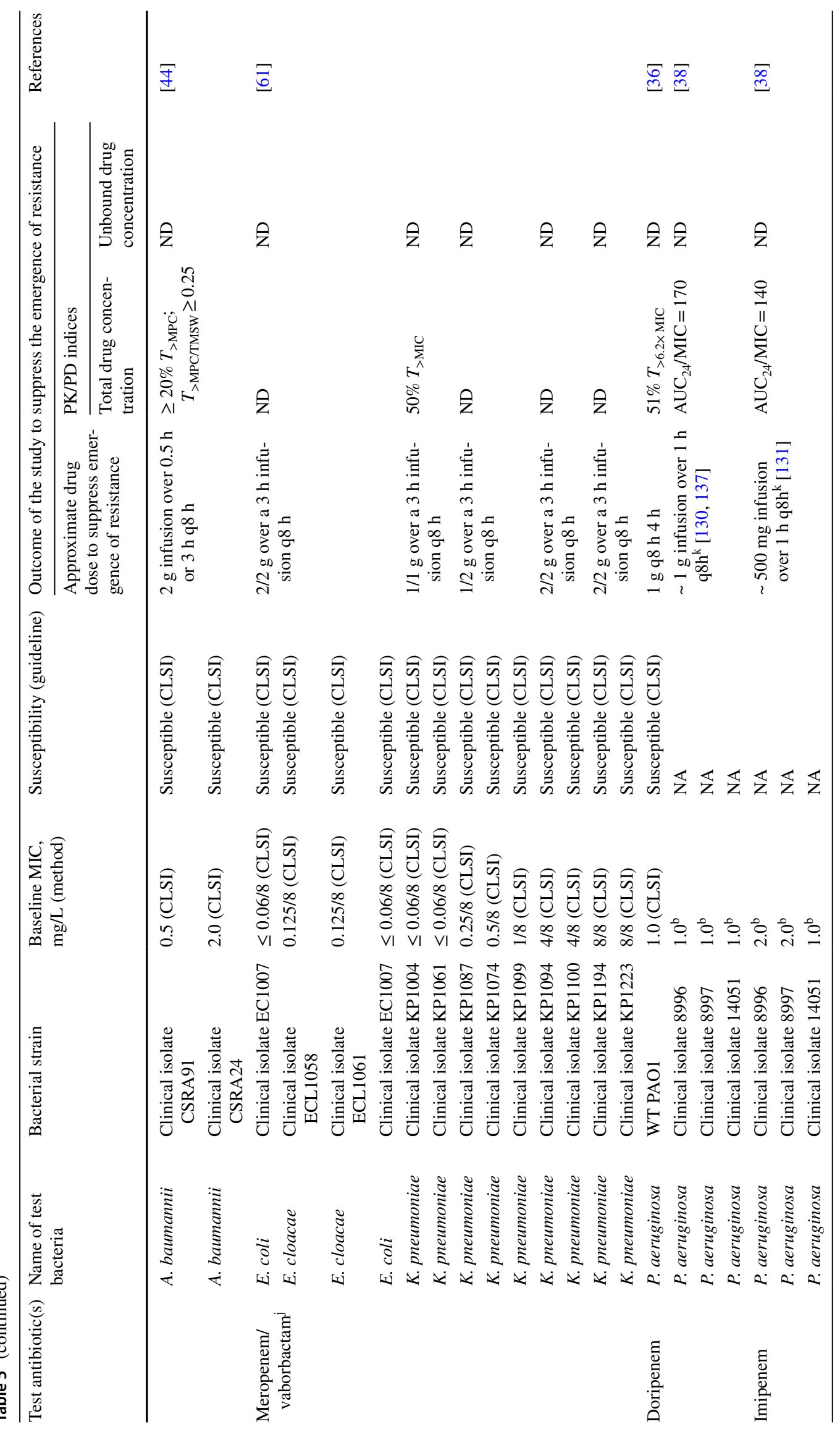




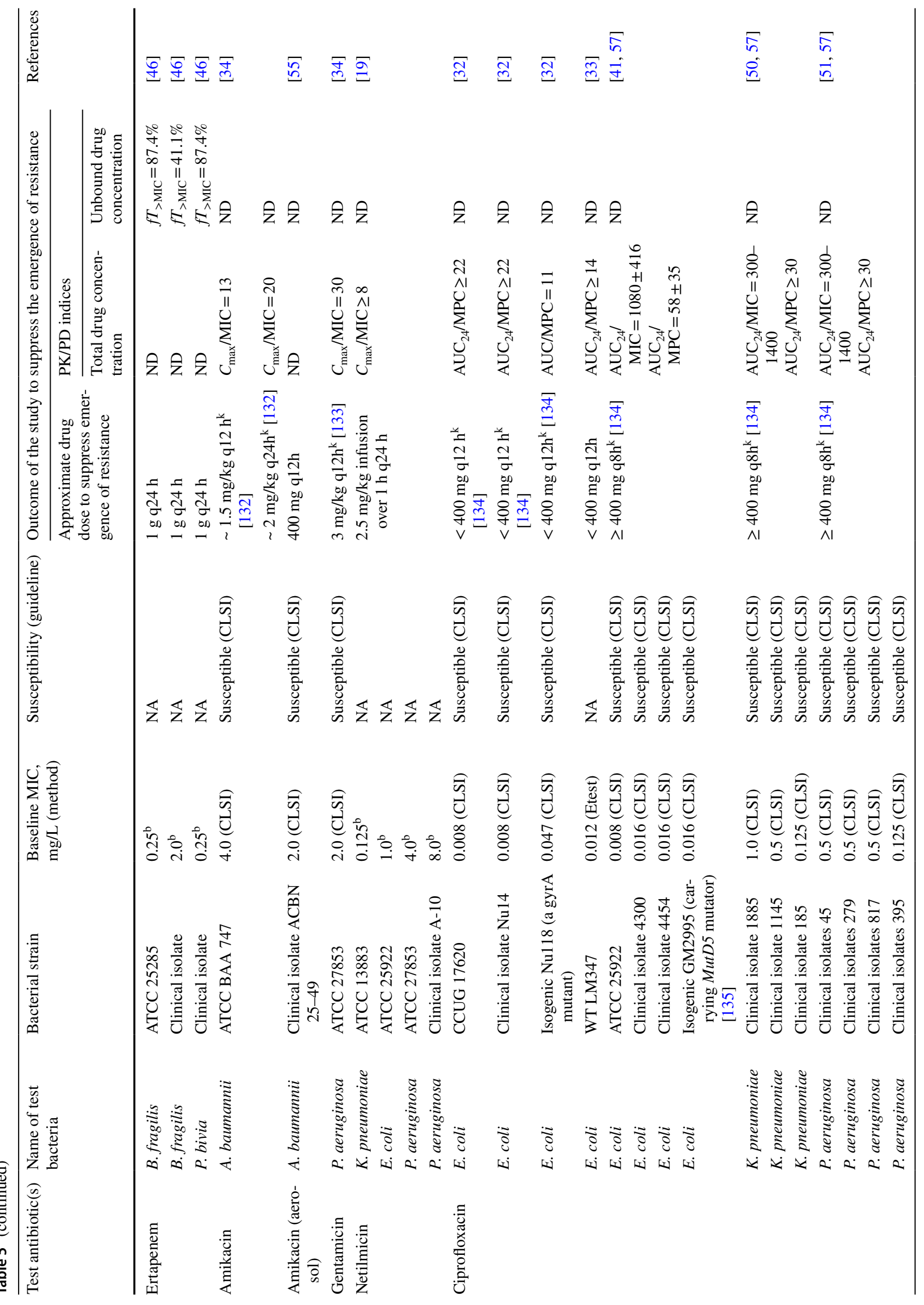




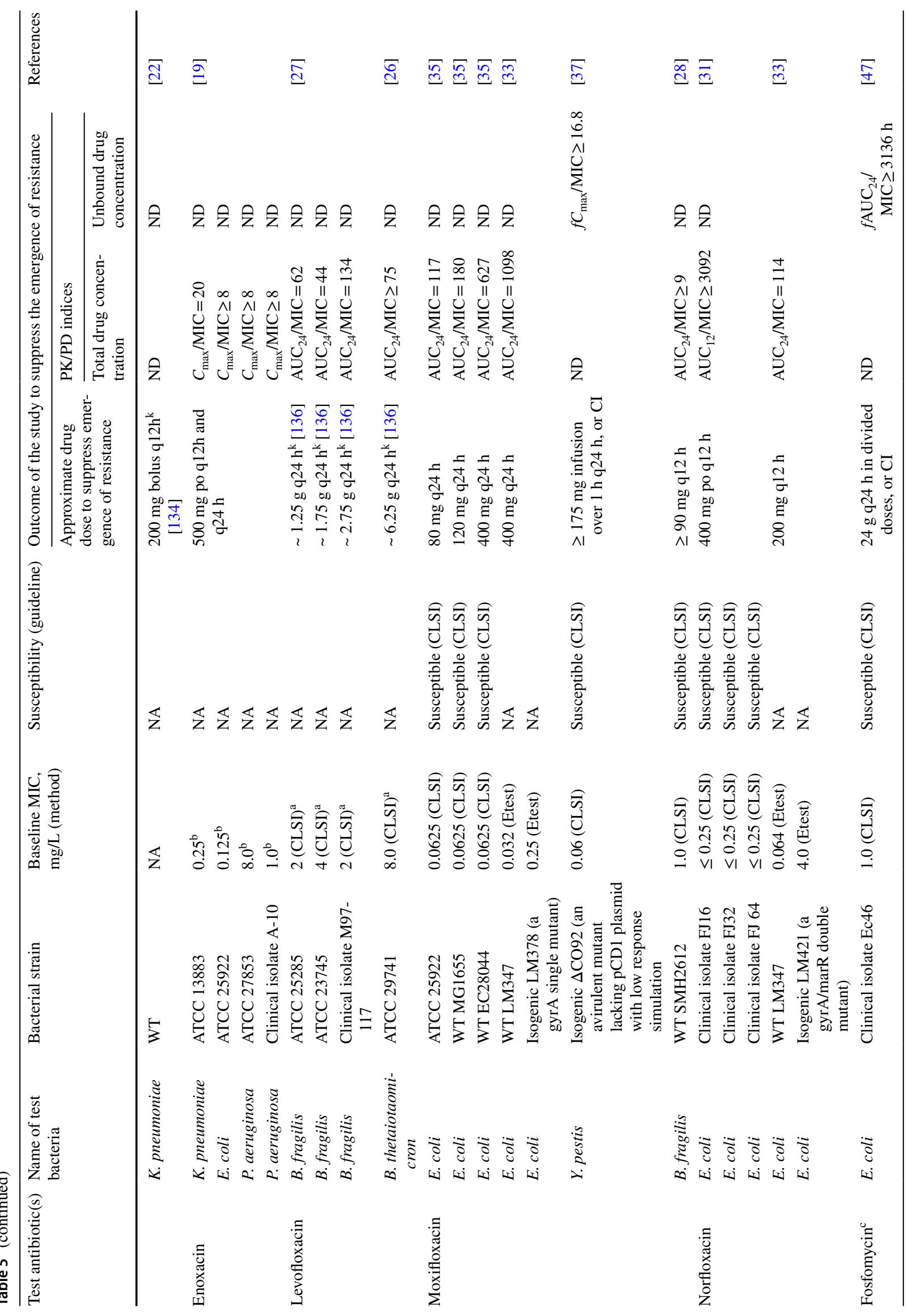




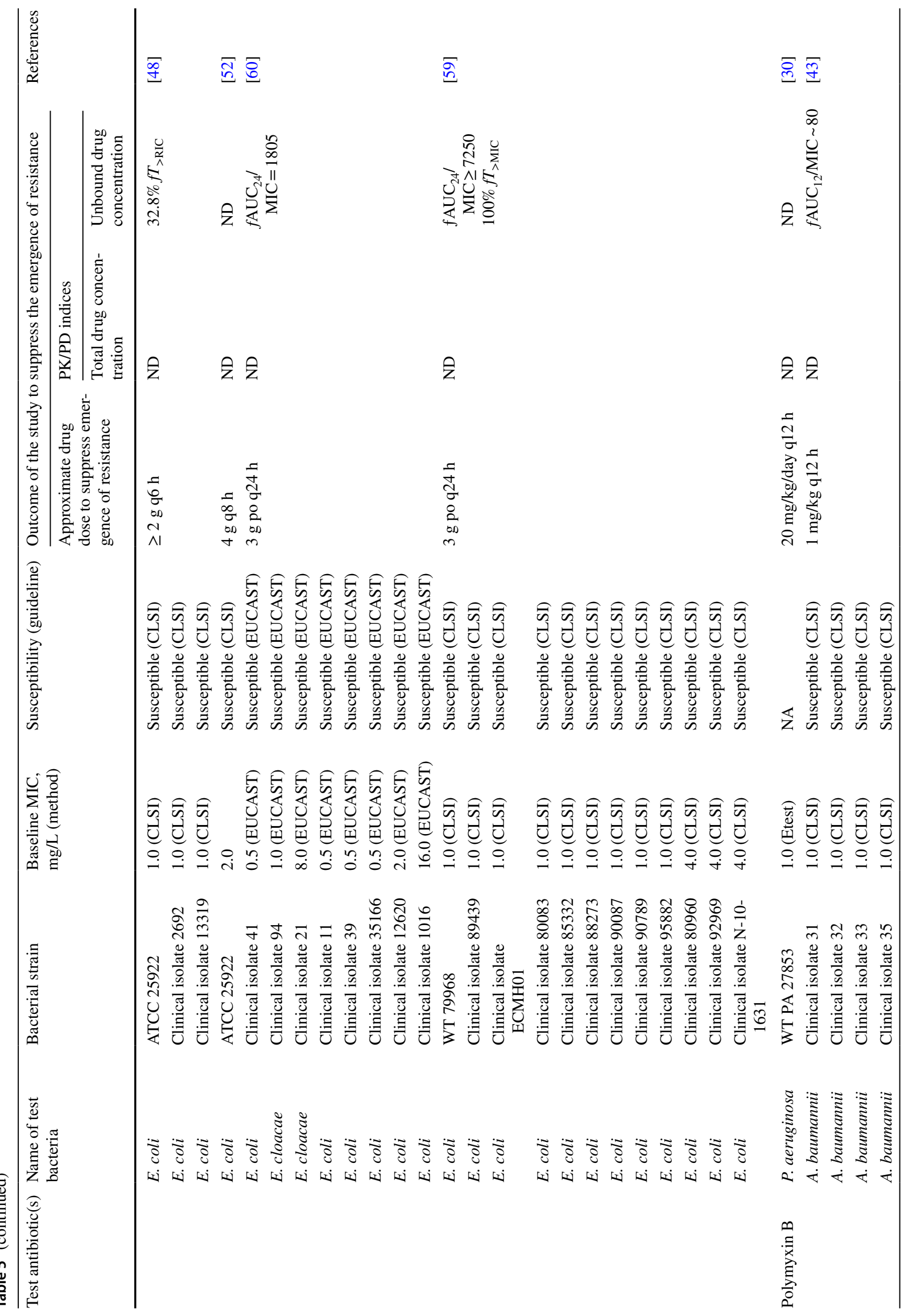




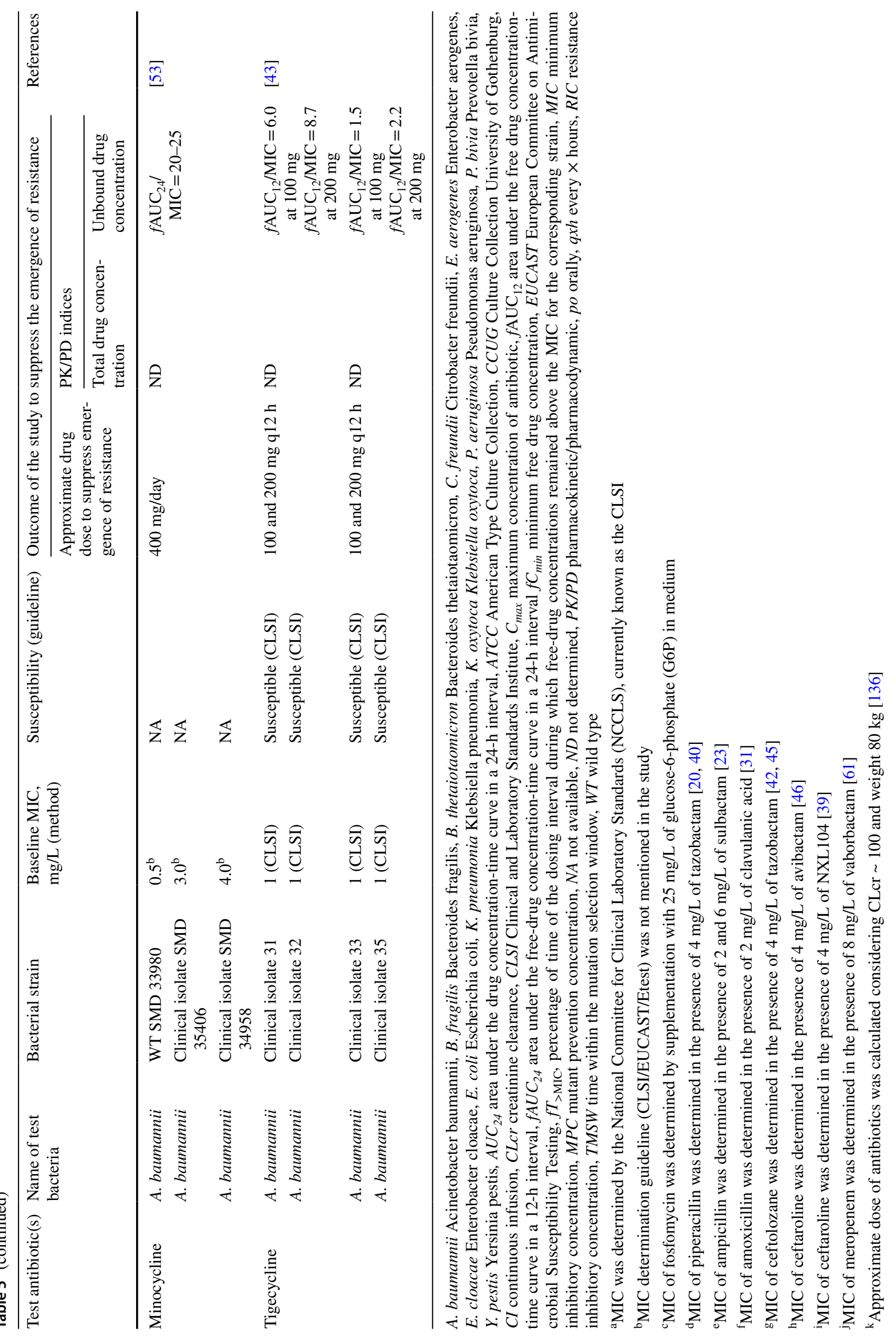




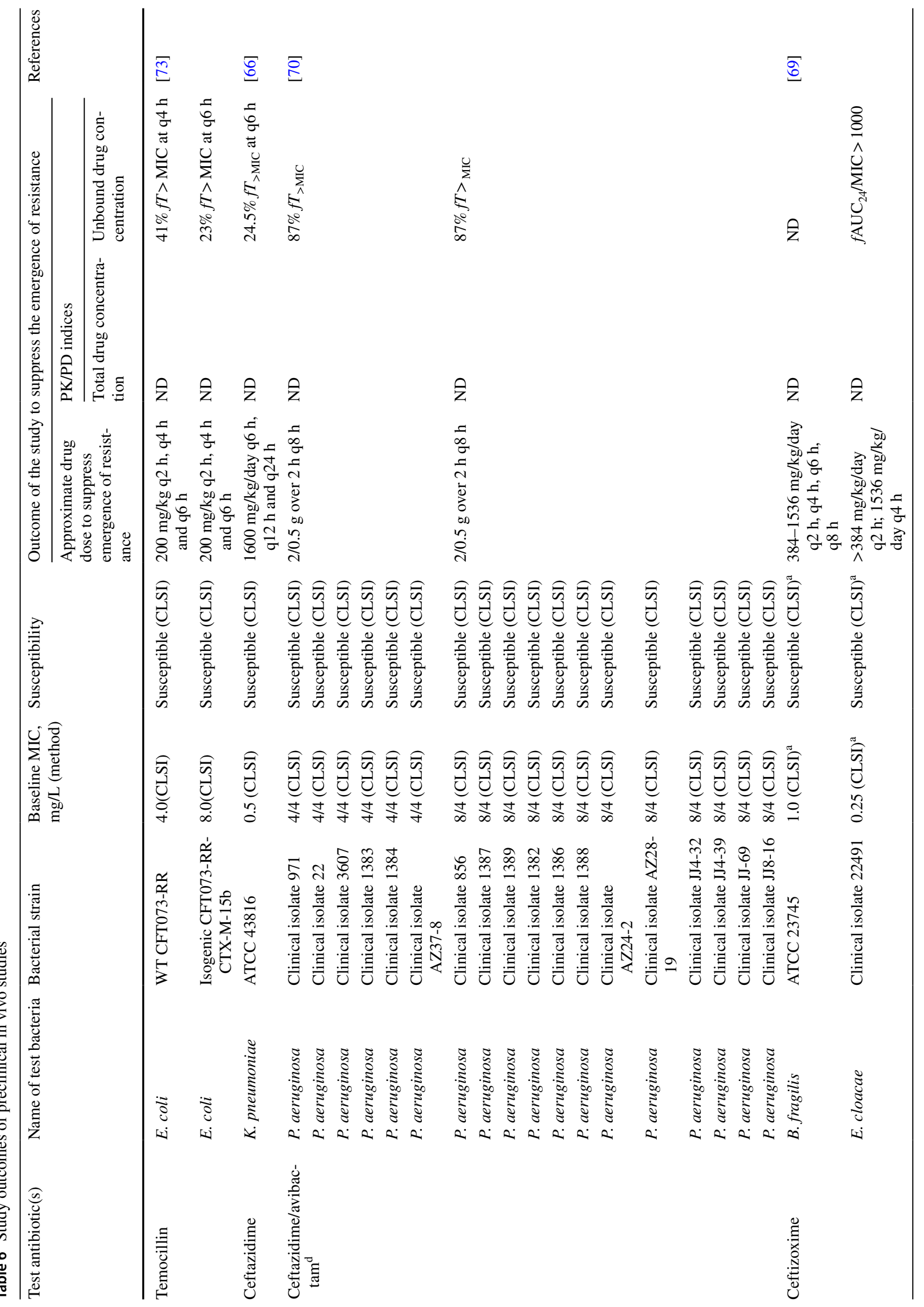




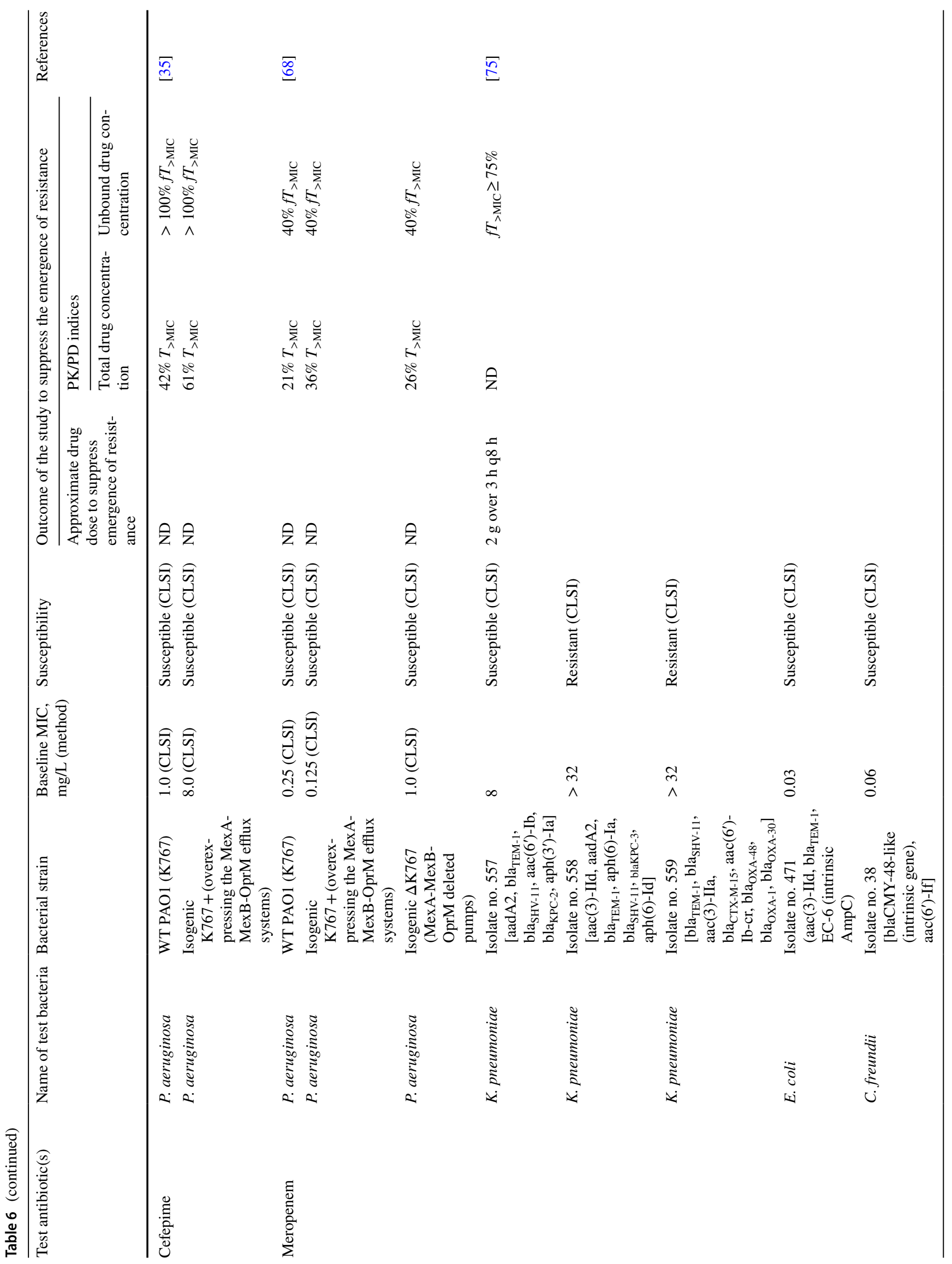




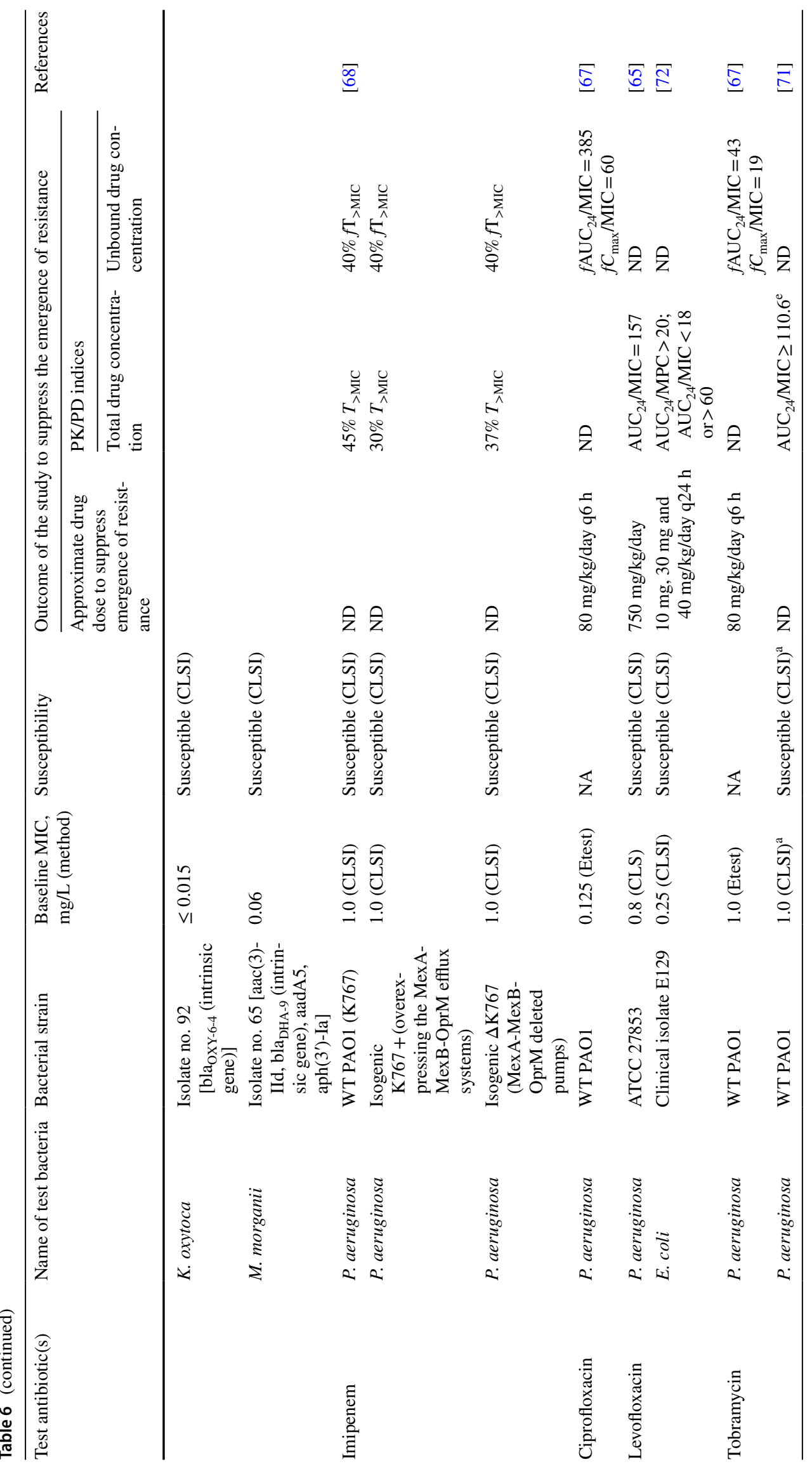




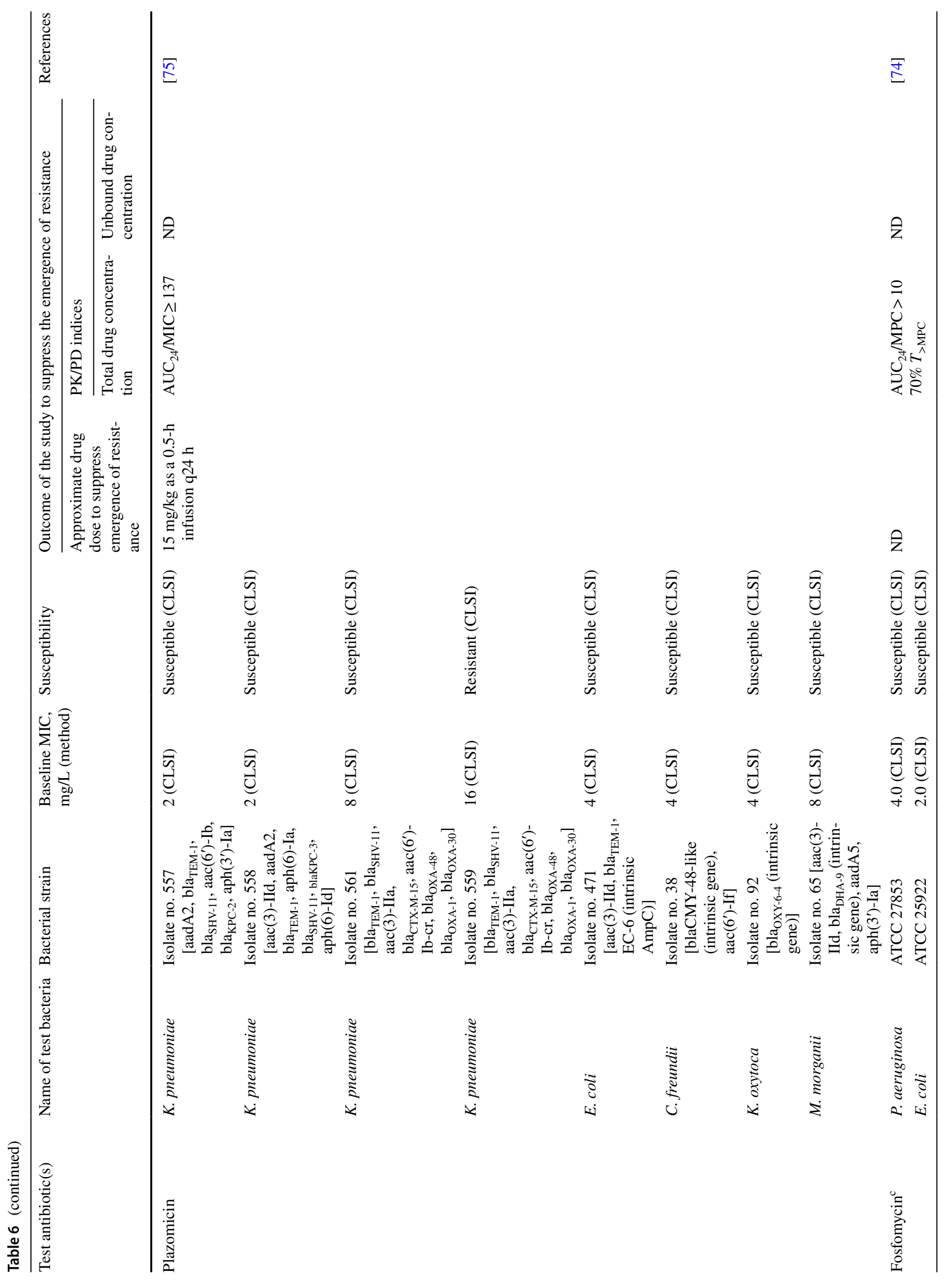




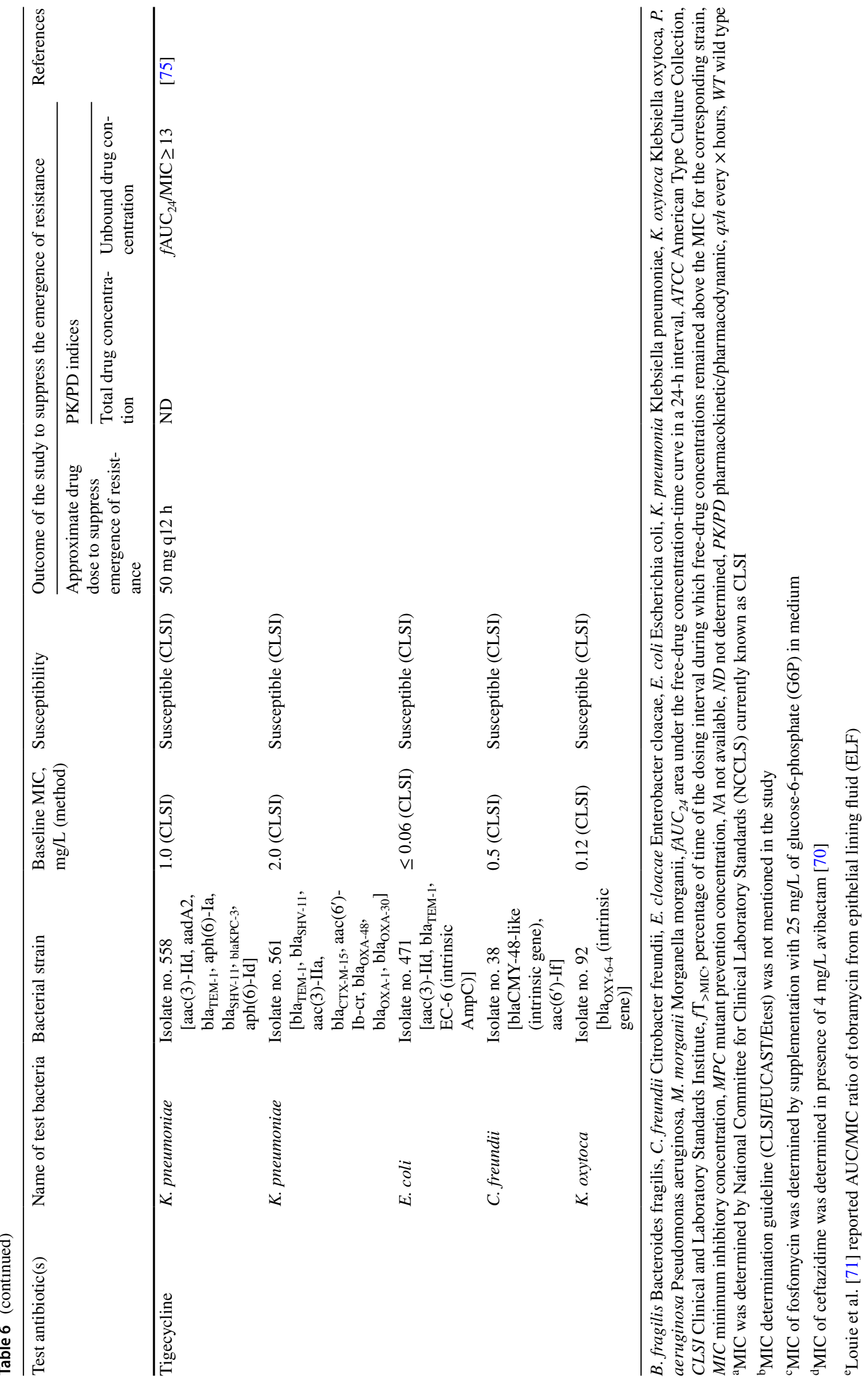




\subsubsection{Fluoroquinolones}

AUC/MIC and AUC/MPC were commonly described PK/ $\mathrm{PD}$ ratios associated with the suppression of emergence of resistance for fluoroquinolones (Table 5). In vitro studies for ciprofloxacin conducted for 24-72 h have reported that an $\mathrm{AUC}_{24} / \mathrm{MPC}$ of between 11 and $\sim 58$ is required to suppress the emergence of resistance against E. coli, K. pneumoniae and $P$. aeruginosa isolates. The $\mathrm{AUC}_{24} / \mathrm{MIC}$ ratio associated with suppression of resistance varies from 300 to 1400 , with no apparent relationship with the AUC/MPC ratio or the bacterial species. On the other hand, a mouse lung infection model study by Maciá et al. [67] reported that a ciprofloxacin $\mathrm{AUC}_{24} / \mathrm{MIC}$ ratio of 385 prevented the emergence of resistance against a wild-type $P$. aeruginosa isolate (MIC $0.125 \mathrm{mg} / \mathrm{L}$ ) (Table 6). However, that study also demonstrated that the same ciprofloxacin exposure failed to suppress the emergence of resistance of a hypermutable $P$. aeruginosa strain (MIC $0.125 \mathrm{mg} / \mathrm{L}$ ). Additionally, a clinical study reported that a higher $\mathrm{AUC}_{24} / \mathrm{MIC}$ ratio of 582 suppressed the emergence of resistance of susceptible $E$. coli, Enterobacter cloacae, Haemophilus influenzae and Serratia marcescens in patients (Table 7) [76].

\subsubsection{Tetracyclines}

As shown in Table 5, only one preclinical dynamic twocompartment in vitro study, conducted by Alfouzan et al. [53], has determined the relationship between minocycline exposure and suppression of emergence resistance of $\mathrm{A}$. $\mathrm{bau}$ mannii. This study suggested that an unbound $\mathrm{AUC}_{24} / \mathrm{MIC}$ ratio of 20-25 was required to suppress the emergence of resistance against three A. baumannii isolates (MICs 0.5, 3 and $4 \mathrm{mg} / \mathrm{L}$ ).

\subsubsection{Polymyxins}

A literature search conducted for this review identified only two preclinical in vitro studies investigating polymyxin B (Table 5) [30, 43]. An in vitro dynamic HFIM study by Tam et al. [30] suggested that a polymyxin B dose of $20 \mathrm{mg} / \mathrm{kg}$ body weight $\left(\mathrm{AUC}_{24} / \mathrm{MIC} \sim 808\right)$ administered twice daily, which is approximately eightfold the current recommended doses, suppressed the emergence of polymyxin B resistance in a wild-type $P$. aeruginosa (MIC $1 \mathrm{mg} / \mathrm{L}$ ), but failed to suppress the emergence of resistance in three other carbapenem-resistant $P$. aeruginosa clinical isolates (MIC ranged from 0.5 to $1 \mathrm{mg} / \mathrm{L}$ ). On the other hand, a dynamic one-compartment in vitro study by Hagihara et al. [43] reported that an unbound $\mathrm{AUC}_{12} / \mathrm{MIC}$ ratio of $\sim 8$ at a simulated twicedaily polymyxin $B$ dose of $1 \mathrm{mg} / \mathrm{kg}$ was required to suppress the emergence of polymyxin resistance in three clinical isolates of carbapenem-resistant A. baumannii (MICs $1 \mathrm{mg} / \mathrm{L}$ ).

\subsubsection{Fosfomycin}

The likely PK/PD ratio to best describe fosfomycin exposures required to suppress emergence of resistance remains unknown. As shown in Table 6, a preclinical rabbit tissue cage infection model study by Pan et al. [74] suggested that an $\mathrm{AUC}_{24} / \mathrm{MPC}$ ratio of $>10$ prevented the emergence of resistant bacteria against laboratory reference strains of $P$. aeruginosa American Type Culture Collection (ATCC) 27853 (MIC $4 \mathrm{mg} / \mathrm{L}$ ) and E. coli ATCC 25922 (MIC $2 \mathrm{mg} / \mathrm{L}$ ). Conversely, resistance was identified in all 15 rabbits for both $P$. aeruginosa and $E$. coli when the $T_{>\mathrm{MPC}}$ was $<70 \%$. One in vitro dynamic HFIM study by DocoboPérez et al. [47] identified a fosfomycin $\mathrm{AUC}_{24} / \mathrm{MIC}$ ratio of $\geq 3136$ suppressed the resistant subpopulation of a susceptible CTX-M-15-producing E. coli (MIC $1 \mathrm{mg} / \mathrm{L}$ ) clinical isolate. In contrast, this study also reported that another CTX-M-15-producing E. coli isolate with the same MIC (MIC $1 \mathrm{mg} / \mathrm{L}$ ) was not suppressed by a similar fosfomycin exposure. On the other hand, a dynamic one-compartment model study by VanScoy et al. [48] suggested that a new PK/PD index, the percentage of the dosing interval that the fosfomycin concentrations remained above the resistance inhibitory concentration (RIC; $f \% T_{>\mathrm{RIC}}$ ), was a better predictor to describe the exposure required for the suppression of emergence of resistance (Table 5). According to their study, a dose $\geq 2$ g every $6 \mathrm{~h}$ suppressed the emergence of one susceptible E. coli ATCC strain (MIC $1 \mathrm{mg} / \mathrm{L}$ ) and two E. coli clinical isolates (MIC for both isolates $1 \mathrm{mg} / \mathrm{L}$ ) when the $\% f T_{>\text {RIC }}$ was more than 32.8 .

\section{Discussion}

Our systematic review, based on 56 preclinical (in vitro and in vivo) and 2 clinical studies, details the antibiotic exposures reported to suppress the emergence of antibiotic resistant Gram-negative bacteria. The results highlight the potential for intraspecies variability of antibiotic exposures required for suppression of resistance that may be independent of the MIC.

The included preclinical studies in this systematic review have reported that the $\beta$-lactam exposures of $f C_{\text {min }} / \mathrm{MIC} \geq 6$ achieved by intermittent infusion suppressed the emergence of resistance of highly susceptible isolates [29, 40, 49, 54, $58]$ and with lower initial inoculum $\left(\sim 10^{4} \mathrm{CFU} / \mathrm{mL}\right)$ [40]. However, the preclinical study has also shown that resistance emergence to $\beta$-lactam antibiotics may occur with an exposure less than a $C_{\min } / \mathrm{MIC}$ of 4 against the clinically relevant bacterial densities as high as $\sim 10^{8} \mathrm{CFU} / \mathrm{ml}$ [58] frequently encountered in patients with ventilator-associated pneumonia (VAP) [138]. In contrast, the exposure needed for optimal clinical cure varies between $>45 \% f T_{>\text {MIC }}$ 
Table 7 Clinical studies of antibiotic exposures and PK/PD indices for suppression of resistance emergence against Gram-negative bacteria

\begin{tabular}{|c|c|c|c|c|c|c|c|c|}
\hline \multirow[t]{3}{*}{ Test antibiotics } & \multirow[t]{3}{*}{$\begin{array}{l}\text { Source of } \\
\text { isolates }\end{array}$} & \multirow[t]{3}{*}{$\begin{array}{l}\text { Name of } \\
\text { bacteria }\end{array}$} & \multirow{3}{*}{$\begin{array}{l}\text { Baseline } \\
\text { MIC, mg/L } \\
\text { (method) }\end{array}$} & \multirow[t]{3}{*}{$\begin{array}{l}\text { Susceptibility } \\
\text { (method) }\end{array}$} & \multicolumn{3}{|c|}{$\begin{array}{l}\text { Outcome of the study to suppress the emer- } \\
\text { gence of resistance }\end{array}$} & \multirow[t]{3}{*}{ References } \\
\hline & & & & & \multirow{2}{*}{$\begin{array}{l}\text { Drug dose } \\
\text { to suppress } \\
\text { emergence of } \\
\text { resistance }\end{array}$} & \multicolumn{2}{|l|}{$\mathrm{PK} / \mathrm{PD}$ indices } & \\
\hline & & & & & & $\begin{array}{l}\text { Total drug } \\
\text { concentration }\end{array}$ & $\begin{array}{l}\text { Free drug } \\
\text { concentra- } \\
\text { tion }\end{array}$ & \\
\hline \multirow[t]{4}{*}{ Cefmenoxime } & \multirow[t]{4}{*}{$\begin{array}{l}\text { Tracheal aspi- } \\
\text { rates }\end{array}$} & E. coli & 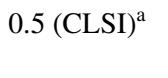 & $\begin{array}{l}\text { Susceptible } \\
(\text { CLSI })^{\mathrm{a}}\end{array}$ & \multirow[t]{4}{*}{$\begin{array}{l}1-2 \mathrm{~g} \mathrm{q} 4 \mathrm{~h} \text { or } \\
\mathrm{q} 6 \mathrm{~h}\end{array}$} & \multirow[t]{4}{*}{$\begin{array}{l}\mathrm{AUC}_{24} / \\
\quad \mathrm{MIC}=668\end{array}$} & \multirow[t]{4}{*}{ ND } & \multirow[t]{4}{*}{ [76] } \\
\hline & & K. pneumoniae & $1.0(\mathrm{CLSI})^{\mathrm{a}}$ & $\begin{array}{l}\text { Susceptible } \\
(\text { CLSI })^{\mathrm{a}}\end{array}$ & & & & \\
\hline & & P. mirabilis & $3.1(\mathrm{CLSI})^{\mathrm{a}}$ & $\begin{array}{l}\text { Susceptible } \\
(\text { CLSI })^{\mathrm{a}}\end{array}$ & & & & \\
\hline & & H. influenzae & ND & NA & & & & \\
\hline \multirow[t]{4}{*}{ Ceftazidime } & \multirow[t]{4}{*}{$\begin{array}{l}\text { Tracheal aspi- } \\
\text { rates }\end{array}$} & E. cloacae & $8.2(\mathrm{CLSI})^{\mathrm{a}}$ & $\begin{array}{l}\text { Susceptible } \\
(\text { CLSI })^{\mathrm{a}}\end{array}$ & \multirow[t]{4}{*}{$\begin{array}{l}1-2 \mathrm{~g} \mathrm{q} 8 \mathrm{~h} \text { or } \\
\mathrm{q} 12 \mathrm{~h}\end{array}$} & \multirow[t]{4}{*}{$\begin{array}{l}\mathrm{AUC}_{24} / \\
\mathrm{MIC}=5303\end{array}$} & \multirow[t]{4}{*}{ ND } & \multirow[t]{4}{*}{ [76] } \\
\hline & & E. coli & $0.2(\mathrm{CLSI})^{\mathrm{a}}$ & $\begin{array}{l}\text { Susceptible } \\
(\text { CLSI })^{\mathrm{a}}\end{array}$ & & & & \\
\hline & & H. influenzae & $0.4(\mathrm{CLSI})^{\mathrm{a}}$ & $\begin{array}{l}\text { Susceptible } \\
(\text { CLSI })^{\mathrm{a}}\end{array}$ & & & & \\
\hline & & P. mirabilis & $0.1(\mathrm{CLSI})^{\mathrm{a}}$ & $\begin{array}{l}\text { Susceptible } \\
(\text { CLSI })^{\mathrm{a}}\end{array}$ & & & & \\
\hline \multirow[t]{5}{*}{ Ciprofloxacin } & \multirow[t]{4}{*}{$\begin{array}{l}\text { Tracheal aspi- } \\
\text { rates }\end{array}$} & E. cloacae & $0.02(\mathrm{CLSI})^{\mathrm{a}}$ & $\begin{array}{l}\text { Susceptible } \\
(\text { CLSI })^{\mathrm{a}}\end{array}$ & \multirow{5}{*}{$\begin{array}{l}200-300 \mathrm{mg} \\
\text { q12 h } \\
400 \mathrm{mg} \text { q } 8 \mathrm{~h} \text { or } \\
\text { q12 h }\end{array}$} & \multirow[t]{4}{*}{$\begin{array}{l}\mathrm{AUC}_{24} / \\
\quad \mathrm{MIC}=582\end{array}$} & \multirow[t]{4}{*}{ ND } & \multirow[t]{4}{*}{ [76] } \\
\hline & & E. coli & $0.01\left(\right.$ CLSI $^{\mathrm{a}}$ & $\begin{array}{l}\text { Susceptible } \\
(\text { CLSI })^{\mathrm{a}}\end{array}$ & & & & \\
\hline & & H. influenzae & $0.01\left(\right.$ CLSI $^{\mathrm{a}}$ & $\begin{array}{l}\text { Susceptible } \\
(\text { CLSI })^{\mathrm{a}}\end{array}$ & & & & \\
\hline & & S. marcescens & $0.06(\mathrm{CLSI})^{\mathrm{a}}$ & $\begin{array}{l}\text { Susceptible } \\
(\text { CLSI })^{\mathrm{a}}\end{array}$ & & & & \\
\hline & $\begin{array}{l}\text { Any site of } \\
\text { infection } \\
\text { with } P \text {. aer- } \\
\text { uginosa }\end{array}$ & P. aeruginosa & $\leq 0.5^{\mathrm{b}}$ & NA & & $\begin{array}{l}\mathrm{AUIC}_{24} / \\
\quad \mathrm{MIC}>110\end{array}$ & ND & [77] \\
\hline
\end{tabular}

E. cloacae Enterobacter cloacae, E. coli Escherichia coli, H. influenza Haemophilus influenza, K. pneumoniae Klebsiella pneumoniae, $P$. aeruginosa Pseudomonas aeruginosa, P. mirabilis Proteus mirabilis, $S$. marcescens Serratia marcescens, $A U C_{24}$ area under the drug concentration-time curve in a 24-h interval, $A U I C_{24}$ area under the inhibitory concentration-time curve in a 24-h interval, CLSI Clinical and Laboratory Standards Institute, $M I C$ minimum inhibitory concentration, $N A$ not available, $N D$ not determined, $P K / P D$ pharmacokinetic/pharmacodynamic, $q x h$ every $\times$ hours

${ }^{\mathrm{a}} \mathrm{MIC}$ of the strain was determined by the National Committee for Clinical Laboratory Standards (NCCLS) method, currently known as the CLSI

${ }^{\mathrm{b}}$ The method for MIC determination was not described

[78] and a $C_{\min } / \mathrm{MIC} \geq 12$ [79-82]; however, this is likely dependent on the infectious type and patient illness severity [83]. Thus, the antibiotic dose to suppress the emergence of $\beta$-lactam antibiotic resistance for most patients is higher than that required for clinical effect [84-91]. The multicentre Defining Antibiotic Levels in Intensive Care Patients (DALI) study highlights the significant interpatient variability of $\beta$-lactam antibiotic pharmacokinetics in the critically ill patient population, with only $60.4 \%$ of patients with currently used dosing regimens achieving $100 \% f T_{>\text {MIC }}$ [92]. Current pharmacokinetic models based on a limited number of patients would suggest that empiric dosing regimens for many $\beta$-lactam antibiotics are inadequate to suppress the emergence of resistance. The dose of meropenem, piperacillin/tazobactam and cefepime, for a patient with a creatinine $\mathrm{CL}$ of $\sim 90 \mathrm{~mL} / \mathrm{min} / 1.73 \mathrm{~m}^{2}$, would need to be increased to $1 \mathrm{~g}$ administered 6-hourly, 4/0.5 g administered 4-hourly, and $2 \mathrm{~g}$ administered 6-hourly, respectively, to meet the minimum exposures required to suppress the emergence of resistance [84-91]. However, even these doses may not achieve the exposures required to suppress the emergence of resistance in patients infected with higher MIC pathogens. The COMParative Activity of Carbapenem Testing (COMPACT) study highlights that the carbapenem MIC of infectious pathogens for patients in intensive care is higher than for other patients. In addition, due to altered 
pharmacokinetics present in critically ill patients, the antibiotic exposure required for both clinical effect and suppression of emergence of resistance is higher as a result of reduced susceptibility of bacteria [93]. Although the higher doses required to suppress the emergence of resistance raises the concern for potential toxicity, the antibiotic exposure required for toxicity is generally high (piperacillin $C_{\min } \sim 361 \mathrm{mg} / \mathrm{L}$ [94-96], cefepime $C_{\min } \geq 22 \mathrm{mg} / \mathrm{L}$ [97] and meropenem $C_{\min } \geq 64 \mathrm{mg} / \mathrm{L}$ ).

There are conflicting results with the aminoglycoside exposure required to suppress the emergence of resistance. A $C_{\max } / \mathrm{MIC}$ ratio of between 20 (amikacin administered once daily against $A$. baumannii) and 32 (gentamicin administered twice daily against $P$. aeruginosa) have been reported to suppress the emergence of resistance $[34,55]$. Moreover, a $C_{\max } / \mathrm{MIC}$ ratio of 15 (amikacin administered once daily) was associated with microbiological success in the group of patients with VAP [98]. In contrast, a lower $C_{\max }$ ' MIC of 8-10 has been shown to improve clinical cure rates in patients with nosocomial pneumonia [99], urinary tract infection, lower respiratory tract infection, cutaneous infection, and intra-abdominal infection [100]. On the other hand, an $\mathrm{AUC}_{24} / \mathrm{MIC}$ ratio of 110 in a murine pneumonia model has also been associated with the suppression of emergence of resistance [71]. This is similar to the $\mathrm{AUC}_{24} / \mathrm{MIC}$ of 120 associated with improved clinical cure in patients with $P$. aeruginosa bacteraemia [101]. Thus, it would appear that the exposure required to suppress the emergence of antibiotic resistance in vitro is higher than that required for clinical efficacy. Moreover, to adequately achieve target peak drug concentrations, the recommended weight-based $7 \mathrm{mg} / \mathrm{kg}$ of tobramycin and gentamicin once-daily regimen was based on PK data derived from a general patient population for the treatment of Gram-negative infections [102, 103]. As a result, current aminoglycoside once-daily dosing regimens may not achieve the exposure required for clinical cure in critically ill patients due to differences in the PK, as shown by Rea et al. [104]. A study by Roger et al. [105] in 63 ICU patients with severe sepsis reported that increasing the dose to $8 \mathrm{mg} / \mathrm{kg}$ did not have an appreciable impact to increase the rate of PK/PD target attainment (the rate of target attainment was 100\%). However, this study did not determine the infecting pathogen MIC in most cases, and used the EUCAST breakpoint of $P$. aeruginosa for assessing the $C_{\max }$ /MIC ratio [105].

Fluoroquinolone resistance emergence is thought to be primarily related to de novo mutations. Since concentrations above the MPC suppress selective proliferation of first-step mutants, the MPC may appropriately describe the concentration of a fluoroquinolone that will suppress the emergence of resistance [106, 107]. Fluoroquinolone exposures within the MSW, the concentration range between the MIC and MPC, have been shown to promote resistance emergence
[107]. Thus, fluoroquinolone dosing should aim to minimize the time the concentration remains within the MSW to minimize the risk of amplifying resistant bacterial populations. A pharmacodynamic target $f T_{\mathrm{MSW}}$ of $<20 \%$ is associated with suppression of emergence of resistance [106] that is clinically achievable; an intravenous ciprofloxacin dose of $400 \mathrm{mg}$ administered three times daily would likely be sufficient to suppress the emergence of resistance against a bacterial isolate with an MIC of $\leq 0.125 \mathrm{mg} / \mathrm{L}$ for most patients [108-110].

The suppression of polymyxin B resistance emergence against carbapenem-resistant isolates has been described for A. baumannii $\left(\mathrm{AUC}_{24} / \mathrm{MIC} \sim 80\right)$ [43], but not for P. aeruginosa with an $\mathrm{AUC}_{24} / \mathrm{MIC}$ exposure $>800$ [30]. Thus, targeting the exposure required for optimal bactericidal activity $\left(\mathrm{AUC}_{12} / \mathrm{MIC}>50\right)$ may also suppress the emergence of resistance against $A$. baumannii [111]. This is clinically achievable with polymyxin $B$ doses of $1.5 \mathrm{mg} / \mathrm{kg}$ administered twice daily [112]; however, this may be limited by nephrotoxicity that may occur with daily doses $>250 \mathrm{mg}$ [113]. Polymyxin B monotherapy may be insufficient to suppress the emergence of resistance when used to treat $P$. aeruginosa infections. Importantly, no dosing regimen of colistin has been shown to suppress the emergence of resistance, which may be related to the slow conversion of the prodrug to the active compound $[114,115]$.

A fosfomycin exposure of an $\mathrm{AUC}_{24} / \mathrm{MIC} \geq 3136$ has been shown to suppress the emergence of resistance for $E$. coli and $E$. cloacae isolates with an MIC $\leq 8 \mathrm{mg} / \mathrm{L}$. With a breakpoint of $8 \mathrm{mg} / \mathrm{L}$, it may be possible to treat and prevent the emergence of resistance for systemic infections in most patients who receive a dose of $8 \mathrm{~g}$ administered three times daily [116], or to treat a urinary tract infection with a single $3 \mathrm{~g}$ oral dose [60]. However, fosfomycin resistance may emerge during treatment for $K$. pneumoniae or nonfermenting Gram-negative bacterial infections.

Taken together, the PK/PD targets required to suppress the emergence of resistance are higher than that required for clinical efficacy; however, existing data on exposures required to suppress resistance are confounded by various factors. First, many studies determining the exposure required to suppress the emergence of resistance have been conducted in vitro against high bacterial burdens of $\sim 1 \times 10^{8} \mathrm{CFU} / \mathrm{mL}$. This may reflect certain infectious syndromes such as VAP [16], but not necessarily a primary bacteraemia that may have a bacterial burden of up to $1 \times 10^{4} \mathrm{CFU} / \mathrm{mL}$ [117]. The bacterial burden is a key consideration given that the probability of a pre-existing resistant subpopulation increases with a larger bacterial burden. Second, the lack of an immune response in in vitro studies limits the potential application to clinical practice. Reducing the bacterial burden to below $1 \times 10^{5} \mathrm{CFU} / \mathrm{mL}$, as demonstrated in a murine thigh infection [118] and a pneumonia 
[119] model, may result in bacterial CL over $24-48 \mathrm{~h}$. Thus, antibiotic exposures required to suppress the emergence of resistance in vivo may only require the bacterial burden to be reduced to below the threshold for immune CL. However, bacteria also develop mechanisms to evade the host immune response by modulating immune signalling [120] and forming biofilms [121]. Lastly, the antibiotic exposure required for the perceived suppression of emergence of resistance was less for experiments with a duration $<72 \mathrm{~h}$ compared with longer durations. This observation may be in keeping with a study of patients with VAP where a treatment duration of 15 days was associated with an increased risk of resistance emergence compared with 8 days of therapy $(42.1 \%$ vs. $62.3 \% ; p=0.04)$ [122]. Moreover, critically ill patients with $P$. aeruginosa infections receiving $>15$ days of meropenem (OR 10, 95\% CI 1.98-551), piperacillin/tazobactam (OR 4.7, 95\% CI 1.8-12.4), ciprofloxacin (OR 14.5, 95\% CI 2.8-75) or ceftazidime (OR 2.6, 95\% CI 1.1-6) were at an increased risk of emergence of resistance [123].

Nevertheless, there are some limitations in our included studies. First, there was a high degree of experimental design heterogeneity among the included studies, such as different initial bacterial inoculums between studies (e.g. $10^{5}-10^{8} \mathrm{CFU} / \mathrm{mL}$ ), differing experimental durations (e.g. $<24-240 \mathrm{~h}$ ), and different pharmacokinetic simulations performed. Thus, it was difficult to draw a definite conclusion on the PK/PD indices or required antibiotic exposures for suppression of the emergence of resistance. Second, preclinical studies have mostly used susceptible bacterial strains with a low MIC that may not be representative of that bacterial species. However, a maximum effect $\left(E_{\max }\right)$ model revealed that the less susceptible strains displayed lower $E_{\max }$ and higher half maximal effective concentration $\left(\mathrm{EC}_{50}\right)$ for tobramycin effect against $P$. aeruginosa [124]. Third, bacterial growth conditions with the idealized laboratory conditions are extraordinarily different from growth within patients. Thus, it is not unexpected that there are evolved genomic differences between laboratory reference strains and corresponding clinical isolates $[125,126]$. Fourth, few genomic data were available for bacterial strains that have been used for preclinical studies. Nonetheless, this represents current clinical practice where bacterial genomic data are not available for routine patient care. Last, we did not include in vivo studies that described the emergence of antibiotic resistance in anatomical sites distinct from the infecting site (e.g. the impact of antibiotic administration on the gastric microbiota). This may be an important consideration for future infection with a resistant organism; however, it is unclear how improved dosing regimens of systemically administered antibiotics may reduce the risk of resistance emergence in different anatomical sites where commensal bacteria may colonize $[127,128]$.
Due to heterogeneity of the included studies in this systematic review, no clear guidelines for clinical targets that should be used to suppress emergence of resistance can be drawn from the current data. As such, we believe that the following investigations should be prioritized for future research: (1) preclinical model testing of whether PK/PD targets associated with suppression of emergence of resistance remain accurate in bacterial strains with higher MICs; (2) preclinical studies using suboptimal PK/PD exposures and the correlation of phenotypic emergence of resistance with genomic data; and (3) clinical and bacteriological outcome data associated with achieving the aforementioned $\mathrm{PK} / \mathrm{PD}$ targets associated with suppression of emergence of resistance.

\section{Conclusions}

This systematic review found that the antibiotic exposures for various classes of antibiotics reported to suppress the emergence of Gram-negative bacteria resistance were generally higher than exposures achievable by recommended antibiotic dosing regimens for clinical cure: $\beta$-lactam, $C_{\min }$ ' MIC $\geq 4$; aminoglycosides, $C_{\max } / \mathrm{MIC}$ ratio $\geq 20$; fluoroquinolones, $\mathrm{AUC}_{24} / \mathrm{MPC} \geq 35$; tetracyclines, $\mathrm{AUC}_{24} / \mathrm{MIC}$ ratio $\geq 50$; polymyxin $\mathrm{B}, \mathrm{AUC}_{24} / \mathrm{MIC} \geq 808$; and fosfomycin, $\mathrm{AUC}_{24} / \mathrm{MIC} \geq 3136$. In addition, the use of high antibiotic dosing that targets the thresholds required to suppress the emergence of resistance should be balanced with the potential risk for concentration-dependent adverse events. Optimization of alternative dosing regimens, such as the use of prolonged or continuous infusions of $\beta$-lactam antibiotics, should be considered to improve the probability of achieving the required antibiotic exposure to attain PK/PD indices for suppression of emergence of resistance; however, factors such as bacterial burden, MIC, and altered pharmacokinetics should be considered for optimization purposes.

Acknowledgements Chandra Datta Sumi would like to acknowledge the University of Queensland International Scholarship (living allowance) and University of Queensland Research Training Tuition Fee Offset scholarship; Aaron J. Heffernan would like to acknowledge funding from a Griffith School of Medicine Research Higher degree scholarship; Fekade B. Sime acknowledges funding from the University of Queensland Post-Doctoral Fellowship (W. T. Allen Bequest); and Jason Roberts would like to acknowledge funding for a National Health and Medical Research Council (NHMRC) Centre of Research Excellence (APP1099452), an NHMRC Project Grant (APP1062040) and a Practitioner Fellowship (APP1117065).

\section{Compliance with Ethical Standards}

Conflict of interest Chandra Datta Sumi, Aaron J. Heffernan, Jeffrey Lipman, Jason A. Roberts, and Fekade B. Sime have no conflicts of interest to declare. 
Funding No external funding was used in the preparation of this review.

\section{References}

1. Ferri M, Ranucci E, Romagnoli P, Giaccone V. Antimicrobial resistance: a global emerging threat to public health systems. Crit Rev Food Sci Nutr. 2017;57(13):2857-76.

2. Davies J, Davies D. Origins and evolution of antibiotic resistance. Microbiol Mol Biol Rev. 2010;74(3):417-33.

3. Miller SI. Antibiotic resistance and regulation of the gram-negative bacterial outer membrane barrier by host innate immune molecules. MBio. 2016;7(5):e01541-16.

4. Vasoo S, Barreto JN, Tosh PK. Emerging issues in gram-negative bacterial resistance: an update for the practicing clinician. Mayo Clin Proc. 2015;90(3):395-403.

5. Falagas ME, Bliziotis IA. Pandrug-resistant Gram-negative bacteria: the dawn of the post-antibiotic era? Int J Antimicrob Agents. 2007;29(6):630-6.

6. Founou RC, Founou LL, Essack SY. Clinical and economic impact of antibiotic resistance in developing countries: a systematic review and meta-analysis. PLoS One. 2017;12(12):e0189621.

7. Cabot G, Bruchmann S, Mulet X, et al. Pseudomonas aeruginosa ceftolozane-tazobactam resistance development requires multiple mutations leading to overexpression and structural modification of AmpC. Antimicrob Agents Chemother. 2014;58(6):3091-9.

8. Shields RK, Chen L, Cheng S, et al. Emergence of ceftazidime-avibactam resistance due to plasmid-borne blakpc-3 mutations during treatment of carbapenem-resistant Klebsiella pneumoniae infections. Antimicrob Agents Chemother. 2017;61(3):e02097-116.

9. Coates A, Hu Y, Bax R, Page C. The future challenges facing the development of new antimicrobial drugs. Nat Rev Drug Discov. 2002;1(11):895-910.

10. Fernandes P, Martens E. Antibiotics in late clinical development. Biochem Pharmacol. 2017;133:152-63.

11. Bulik CC, Christensen H, Li P, Sutherland CA, Nicolau DP, Kuti JL. Comparison of the activity of a human simulated, high-dose, prolonged infusion of meropenem against Klebsiella pneumoniae producing the KPC carbapenemase versus that against Pseudomonas aeruginosa in an in vitro pharmacodynamic model. Antimicrob Agents Chemother. 2010;54(2):804-10.

12. Ungphakorn W, Tängdén T, Sandegren L, Nielsen EI. A pharmacokinetic-pharmacodynamic model characterizing the emergence of resistant Escherichia coli subpopulations during ertapenem exposure. J Antimicrob Chemother. 2016;71(9):2521-33.

13. Mouton JW, Muller AE, Canton R, et al. MIC-based dose adjustment: facts and fables. J Antimicrob Chemother. 2018;73(3):564-8.

14. Gugel J, Dos Santos Pereira A, Pignatari AC, Gales AC. Betalactam MICs correlate poorly with mutant prevention concentrations for clinical isolates of Acinetobacter spp. and Pseudomonas aeruginosa. Antimicrob Agents Chemother. 2006;50(6):2276-7.

15. Hansen GT, Zhao X, Drlica K, Blondeau JM. Mutant prevention concentration for ciprofloxacin and levofloxacin with Pseudomonas aeruginosa. Int J Antimicrob Agents. 2006;27(2):120-4.

16. Baldesi O, Michel F, Guervilly C, Embriaco N, Granfond A, et al. Bacterial ventilator-associated pneumonia: bronchoalveolar lavage results are not influenced by dilution. Intensive Care Med. 2009;35(7):1210-5.
17. Moher D, Liberati A, Tetzlaff J, Altman DG, PRISMA Group. Preferred reporting items for systematic reviews and meta-analyses: the PRISMA statement. PLoS Med. 2009;6(7):e1000097.

18. Fernández-Cruz ML, Hernández-Moreno D, Catalán J, et al. Quality evaluation of human and environmental toxicity studies performed with nanomaterials - the GUIDEnano approach. Environ Sci Nano. 2018;2:381-97.

19. Blaser J, Stone BB, Groner MC, Zinner SH. Comparative study with enoxacin and netilmicin in a pharmacodynamic model to determine importance of ratio of antibiotic peak concentration to MIC for bactericidal activity and emergence of resistance. Antimicrob Agents Chemother. 1987;31(7):1054-60.

20. Strayer AH, Gilbert DH, Pivarnik P, Medeiros AA, et al. Pharmacodynamics of piperacillin alone and in combination with tazobactam against piperacillin-resistant and -susceptible organisms in an in vitro model of infection. Antimicrob Agents Chemother. 1994;38(10):2351-6.

21. Palmer SM, Kang SL, Cappelletty DM, Rybak MJ. Bactericidal killing activities of cefepime, ceftazidime, cefotaxime, and ceftriaxone against Staphylococcus aureus and beta-lactamase-producing strains of Enterobacter aerogenes and Klebsiella pneumoniae in an in vitro infection model. Antimicrob Agents Chemother. 1995;39(8):1764-71.

22. Garrison MW, Anderson DE, Campbell DM, et al. Stenotrophomonas maltophilia: emergence of multidrug-resistant strains during therapy and in an in vitro pharmacodynamic chamber model. Antimicrob Agents Chemother. 1996;40(12):2859-64.

23. Lamp KC, Vickers MK. Pharmacodynamics of ampicillin-sulbactam in an in vitro infection model against Escherichia coli strains with various levels of resistance. Antimicrob Agents Chemother. 1998;42(2):231-5.

24. Cappelletty DM. Evaluation of several dosing regimens of cefepime, with various simulations of renal function, against clinical isolates of Pseudomonas aeruginosa in a pharmacodynamic infection model. Antimicrob Agents Chemother. 1999;43(1):129-33.

25. Tessier PR, Nicolau DP, Onyeji CO, Nightingale CH. Pharmacodynamics of intermittent- and continuous-infusion cefepime alone and in combination with once-daily tobramycin against Pseudomonas aeruginosa in an in vitro infection model. Chemotherapy. 1999;45(4):284-95.

26. Ross GH, Wright DH, Hovde LB, Peterson ML, Rotschafer JC. Fluoroquinolone resistance in anaerobic bacteria following exposure to levofloxacin, trovafloxacin, and sparfloxacin in an in vitro pharmacodynamic model. Antimicrob Agents Chemother. 2001;45(7):2136-40.

27. Peterson ML, Hovde LB, Wright DH, et al. Pharmacodynamics of trovafloxacin and levofloxacin against Bacteroides fragilis in an in vitro pharmacodynamic model. Antimicrob Agents Chemother. 2002;46(1):203-10.

28. Noel AR, Bowker KE, MacGowan AP. Pharmacodynamics of moxifloxacin against anaerobes studied in an in vitro pharmacokinetic model. Antimicrob Agents Chemother. 2005;49(10):4234-9.

29. Tam VH, Schilling AN, Neshat S, Poole K, Melnick DA, Coyle EA. Optimization of meropenem minimum concentration/MIC ratio to suppress in vitro resistance of Pseudomonas aeruginosa. Antimicrob Agents Chemother. 2005;49(12):4920-7.

30. Tam VH, Schilling AN, Vo G, Kabbara S, Kwa AL, Wiederhold NP, et al. Pharmacodynamics of polymyxin B against Pseudomonas aeruginosa. Antimicrob Agents Chemother. 2005;49(9):3624-30.

31. Alou L, Aguilar L, Sevillano D, Giménez MJ, Cafini F, Valero E, et al. Urine bactericidal activity against resistant Escherichia coli in an in vitro pharmacodynamic model simulating urine concentrations obtained after 2000/125 mg sustained-release 
co-amoxiclav and $400 \mathrm{mg}$ norfloxacin administration. J Antimicrob Chemother. 2006;57(4):714-9.

32. Olofsson SK, Marcusson LL, Komp Lindgren P, Hughes D, Cars O. Selection of ciprofloxacin resistance in Escherichia coli in an in vitro kinetic model: relation between drug exposure and mutant prevention concentration. J Antimicrob Chemother. 2006;57(6):1116-21.

33. Olofsson SK, Marcusson LI, Strömbäck A, Hughes D, Cars O. Dose-related selection of fluoroquinolone-resistant Escherichia coli. J Antimicrob Chemother. 2007;60(4):795-801.

34. Tam VH, Ledesma KR, Vo G, Kabbara S, Lim TP, Nikolaou M. Pharmacodynamic modeling of aminoglycosides against Pseudomonas aeruginosa and Acinetobacter baumannii: identifying dosing regimens to suppress resistance development. Antimicrob Agents Chemother. 2008;52(11):3987-93.

35. Singh R, Ledesma KR, Chang KT, Hou JG, Prince RA, Tam VH. Pharmacodynamics of moxifloxacin against a high inoculum of Escherichia coli in an in vitro infection model. J Antimicrob Chemother. 2009;64(3):556-62.

36. Louie A, Bied A, Fregeau C, Van Scoy B, Brown D, Liu WG, et al. Impact of different carbapenems and regimens of administration on resistance emergence for three isogenic Pseudomonas aeruginosa strains with differing mechanisms of resistance. Antimicrob Agents Chemother. 2010;54(6):2638-45.

37. Louie A, Heine HS, VanScoy B, Eichas A, Files K, Fikes S, et al. Use of an in vitro pharmacodynamic model to derive a moxifloxacin regimen that optimizes kill of Yersinia pestis and prevents emergence of resistance. Antimicrob Agents Chemother. 2011;55(2):822-30.

38. Firsov AA, Gilbert D, Greer K, Portnoy YA, Zinner SH. Comparative pharmacodynamics and antimutant potentials of doripenem and imipenem with ciprofloxacin-resistant Pseudomonas aeruginosa in an in vitro model. Antimicrob Agents Chemother. 2012;56(3):1223-8.

39. Louie A, Castanheira M, Liu W, Grasso C, Jones RN, Williams $\mathrm{G}$, et al. Pharmacodynamics of $\beta$-lactamase inhibition by NXL104 in combination with ceftaroline: examining organisms with multiple types of $\beta$-lactamases. Antimicrob Agents Chemother. 2012;56(1):258-70.

40. Felton TW, Goodwin J, O'Connor L, Sharp A, Gregson L, Livermore J, et al. Impact of bolus dosing versus continuous infusion of piperacillin and tazobactam on the development of antimicrobial resistance in Pseudomonas aeruginosa. Antimicrob Agents Chemother. 2013;57(12):5811-9.

41. Firsov AA, Strukova EN, Shlykova DS, Portnoy YA, Kozyreva VK, Edelstein MV, et al. Bacterial resistance studies using in vitro dynamic models: the predictive power of the mutant prevention and minimum inhibitory antibiotic concentrations. Antimicrob Agents Chemother. 2013;57(10):4956-62.

42. Vanscoy B, Mendes RE, Castanheira M, McCauley J, Bhavnani SM, Forrest A, et al. Relationship between ceftolozanetazobactam exposure and drug resistance amplification in a hollow-fiber infection model. Antimicrob Agents Chemother. 2013;57(9):4134-8.

43. Hagihara M, Housman ST, Nicolau DP, Kuti JL. In vitro pharmacodynamics of polymyxin B and tigecycline alone and in combination against carbapenem-resistant Acinetobacter baumannii. Antimicrob Agents Chemother. 2014;58(2):874-9.

44. Li X, Wang L, Zhang XJ, et al. Evaluation of meropenem regimens suppressing emergence of resistance in Acinetobacter baumannii with human simulated exposure in an in vitro intravenous-infusion hollow-fiber infection model. Antimicrob Agents Chemother. 2014;58(11):6773-81.

45. VanScoy BD, Mendes RE, Castanheira M, McCauley J, Bhavnani SM, Jones RN, et al. Relationship between ceftolozane-tazobactam exposure and selection for Pseudomonas aeruginosa resistance in a hollow-fiber infection model. Antimicrob Agents Chemother. 2014;58(10):6024-31.

46. Werth BJ, Rybak MJ. Ceftaroline plus avibactam demonstrates bactericidal activity against pathogenic anaerobic bacteria in a one-compartment in vitro pharmacokinetic/pharmacodynamic model. Antimicrob Agents Chemother. 2014;58(1):559-62.

47. Docobo-Pérez F, Drusano GL, Johnson A, Goodwin J, et al. Pharmacodynamics of fosfomycin: insights into clinical use for antimicrobial resistance. Antimicrob Agents Chemother. 2015;59(9):5602-10.

48. VanScoy BD, McCauley J, Ellis-Grosse EJ, Okusanya OO, Bhavnani SM, Forrest A, et al. Exploration of the pharmacokineticpharmacodynamic relationships for fosfomycin efficacy using an in vitro infection model. Antimicrob Agents Chemother. 2015;59(12):7170-7.

49. Bergen PJ, Bulitta JB, Kirkpatrick CMJ, Rogers KE, McGregor MJ, Wallis SC, et al. Effect of different renal function on antibacterial effects of piperacillin against Pseudomonas aeruginosa evaluated via the hollow-fibre infection model and mechanismbased modelling. J Antimicrob Chemother. 2016;71(9):2509-20.

50. Strukova EN, Portnoy YA, Romanov AV, Edelstein MV, Zinner SH, Firsov AA. Searching for the optimal predictor of ciprofloxacin resistance in Klebsiella pneumoniae by using in vitro dynamic models. Antimicrob Agents Chemother. 2016;60(3):1208-15.

51. Strukova EN, Portnoy YA, Zinner SH, Firsov AA. Predictors of bacterial resistance using in vitro dynamic models: area under the concentration-time curve related to either the minimum inhibitory or mutant prevention antibiotic concentration. J Antimicrob Chemother. 2016;71(3):678-84.

52. VanScoy B, McCauley J, Bhavnani SM, Ellis-Grosse EJ, Ambrose PG. Relationship between fosfomycin exposure and amplification of Escherichia coli subpopulations with reduced susceptibility in a hollow-fiber infection model. Antimicrob Agents Chemother. 2016;60(9):5141-5.

53. Alfouzan WA, Noel AR, Bowker KE, Attwood MLG, Tomaselli SG, MacGowan AP. Pharmacodynamics of minocycline against Acinetobacter baumannii studied in a pharmacokinetic model of infection. Int J Antimicrob Agents. 2017;50(6):715-7.

54. Bergen PJ, Bulitta JB, Kirkpatrick CMJ, Rogers KE, McGregor MJ, Wallis SC, et al. Substantial impact of altered pharmacokinetics in critically ill patients on the antibacterial effects of meropenem evaluated via the dynamic hollow-fiber infection model. Antimicrob Agents Chemother. 2017;61(5):e02642.

55. Ghazi IM, Grupper M, Nicolau DP. Antibacterial activity of human simulated epithelial lining fluid concentrations of amikacin inhale alone and in combination with meropenem against Acinetobacter baumannii. Infect Dis. 2017;49(11-12):831-9.

56. Soon RL, Lenhard JR, Bulman ZP, Holden PN, Kelchlin P, Steenbergen JN, et al. In vitro pharmacodynamic evaluation of ceftolozane/tazobactam against beta-lactamase-producing Escherichia coli in a hollow-fibre infection model. Int J Antimicrob Agents. 2017;49(1):25-30.

57. Strukova EN, Portnoy YA, Zinner SH, Firsov AA. Species differences in ciprofloxacin resistance among Gram-negative bacteria: can "anti-mutant" ratios of the area under the concentration-time curve to the MIC be achieved clinically? J Chemother. 2017;29(6):351-7.

58. Tam VH, Chang KT, Zhou J, Ledesma KR, Phe K, Gao S, et al. Determining beta-lactam exposure threshold to suppress resistance development in Gram-negative bacteria. J Antimicrob Chemother. 2017;72(5):1421-8.

59. Zhanel GG, Parkinson K, Higgins S, Denisuik A, Adam H, Pitout $\mathrm{J}$, et al. Pharmacodynamic activity of fosfomycin simulating urinary concentrations achieved after a single 3 -g oral dose versus 
Escherichia coli using an in vitro model. Diagn Microbiol Infect Dis. 2017;88(3):271-5.

60. Abbott IJ, Meletiadis J, Belghanch I, Wijma RA, Kanioura L, Roberts JA, et al. Fosfomycin efficacy and emergence of resistance among Enterobacteriaceae in an in vitro dynamic bladder infection model. J Antimicrob Chemother. 2018;73(3):709-19.

61. Sabet M, Tarazi Z, Rubio-Aparicio D, Nolan TG, Parkinson $\mathrm{J}$, Lomovskaya $\mathrm{O}$, et al. Activity of simulated human dosage regimens of meropenem and vaborbactam against carbapenemresistant enterobacteriaceae in an in vitro hollow-fiber model. Antimicrob Agents Chemother. 2018;62(2):e01969-17.

62. Noel AR, Bowker KE, Attwood M, MacGowan AP. Antibacterial effect of ceftolozane/tazobactam in combination with amikacin against aerobic Gram-negative bacilli studied in an in vitro pharmacokinetic model of infection. J Antimicrob Chemother. 2018;73(9):2411-7.

63. Barber KE, Pogue JM, Warnock HD, Bonomo RA, Kaye KS. Ceftazidime/avibactam versus standard-of-care agents against carbapenem-resistant Enterobacteriaceae harbouring blaKPC in a one-compartment pharmacokinetic/pharmacodynamic model. J Antimicrob Chemother. 2018;73(9):2405-10.

64. Abodakpi H, Chang KT, Gao S, Sanchez-Diaz AM, Canton R, Tam VH. Optimal piperacillin-tazobactam dosing strategies against extended-spectrum-beta-lactamase-producing Enterobacteriaceae. Antimicrob Agents Chemother. 2019;63(2):e01906-18.

65. Jumbe N, Louie A, Leary R, Liu W, Deziel MR, Tam VH, et al. Application of a mathematical model to prevent in vivo amplification of antibiotic-resistant bacterial populations during therapy. J Clin Investig. 2003;112(2):275-85.

66. Bakker-Woudenberg IA, ten Kate MT, Goessens WH, Mouton JW. Effect of treatment duration on pharmacokinetic/pharmacodynamic indices correlating with therapeutic efficacy of ceftazidime in experimental Klebsiella pneumoniae lung infection. Antimicrob Agents Chemother. 2006;50(9):2919-25.

67. Maciá MD, Borrell N, Segura M, Gómez C, Pérez JL, Oliver A. Efficacy and potential for resistance selection of antipseudomonal treatments in a mouse model of lung infection by hypermutable Pseudomonas aeruginosa. Antimicrob Agents Chemother. 2006;50(3):975-83.

68. Ong CT, Tessier PR, Li C, Nightingale CH, Nicolau DP. Comparative in vivo efficacy of meropenem, imipenem, and cefepime against Pseudomonas aeruginosa expressing MexA-MexB-OprM efflux pumps. Diagn Microbiol Infect Dis. 2007;57(2):153-61.

69. Stearne LE, Goessens WH, Mouton JW, Gyssens IC. Effect of dosing and dosing frequency on the efficacy of ceftizoxime and the emergence of ceftizoxime resistance during the early development of murine abscesses caused by Bacteroides fragilis and Enterobacter cloacae mixed infection. Antimicrob Agents Chemother. 2007;51(10):3605-11.

70. Crandon JL, Schuck VJ, Banevicius MA, Beaudoin ME, Nichols WW, Tanudra MA, et al. Comparative in vitro and in vivo efficacies of human simulated doses of ceftazidime and ceftazidimeavibactam against Pseudomonas aeruginosa. Antimicrob Agents Chemother. 2012;56(12):6137-46.

71. Louie A, Liu W, Fikes S, Brown D, Drusano GL. Impact of meropenem in combination with tobramycin in a murine model of Pseudomonas aeruginosa pneumonia. Antimicrob Agents Chemother. 2013;57(6):2788-92.

72. Ni W, Song X, Cui J. Testing the mutant selection window hypothesis with Escherichia coli exposed to levofloxacin in a rabbit tissue cage infection model. Eur J Clin Microbiol Infect Dis. 2014;33(3):385-9.

73. Soubirou JF, Rossi B, Couffignal C, Ruppé E, Chau F, Massias L, et al. Activity of temocillin in a murine model of urinary tract infection due to Escherichia coli producing or not producing the ESBL CTX-M-15. J Antimicrob Chemother. 2015;70(5):1466-72.

74. Pan AJ, Mei Q, Ye Y, Li HR, Liu B, Li JB. Validation of the mutant selection window hypothesis with fosfomycin against Escherichia coli and Pseudomonas aeruginosa: an in vitro and in vivo comparative study. $\mathrm{J}$ Antibiot (Tokyo). 2017;70(2):166-73.

75. Abdelraouf K, Kim A, Krause KM, Nicolau DP. In vivo efficacy of plazomicin alone or in combination with meropenem or tigecycline against Enterobacteriaceae isolates exhibiting various resistance mechanisms in an immunocompetent murine septicemia model. Antimicrob Agents Chemother. 2018;62(8):e01074-116.

76. Thomas JK, Forrest A, Bhavnani SM, Hyatt JM, Cheng A, Ballow $\mathrm{CH}$, et al. Pharmacodynamic evaluation of factors associated with the development of bacterial resistance in acutely ill patients during therapy. Antimicrob Agents Chemother. 1998;42(3):521-7.

77. Hyatt JM, Schentag JJ. Pharmacodynamic modeling of risk factors for ciprofloxacin resistance in Pseudomonas aeruginosa. Infect Control Hosp Epidemiol. 2000;21(1 Suppl):S9-11.

78. Muller AE, Punt N, Mouton JW. Optimal exposures of ceftazidime predict the probability of microbiological and clinical outcome in the treatment of nosocomial pneumonia. J Antimicrob Chemother. 2013;68(4):900-6.

79. MacVane SH, Kuti JL, Nicolau DP. Clinical pharmacodynamics of antipseudomonal cephalosporins in patients with ventilator-associated pneumonia. Antimicrob Agents Chemother. 2014;58(3):1359-64.

80. Tam VH, McKinnon PS, Akins RL, Rybak MJ, Drusano GL. Pharmacodynamics of cefepime in patients with Gram-negative infections. J Antimicrob Chemother. 2002;50(3):425-8.

81. Delattre IK, Taccone FS, Jacobs F, Hites M, Dugernier T, Spapen $\mathrm{H}$, et al. Optimizing beta-lactams treatment in critically-ill patients using pharmacokinetics/pharmacodynamics targets: are first conventional doses effective? Expert Rev Anti Infect Ther. 2017;15(7):677-88.

82. Rhodes NJ, Kuti JL, Nicolau DP, Van Wart S, Nicasio AM, Liu JJ, et al. Defining clinical exposures of cefepime for gram-negative bloodstream infections that are associated with improved survival. Antimicrob Agents Chemother. 2016;60(3):1401-10.

83. Miglis C, Rhodes NJ, Kuti JL, Nicolau DP, Van Wart SA, Scheetz MH. Defining the impact of severity of illness on time above the MIC threshold for cefepime in Gram-negative bacteraemia: a 'Goldilocks' window. Int J Antimicrob Agents. 2017;50(3):487-90.

84. Dhaese SAM, Roberts JA, Carlier M, Verstraete AG, Stove V, DeWaele JJ. Population pharmacokinetics of continuous infusion of piperacillin in critically ill patients. Int J Antimicrob Agents. 2018;51(4):594-600.

85. Alobaid AS, Wallis SC, Jarrett P, Starr T, Stuart J, Lassig-Smith $\mathrm{M}$, et al. Population pharmacokinetics of piperacillin in nonobese, obese, and morbidly obese critically ill patients. Antimicrob Agents Chemother. 2017;61(3):e01276-316.

86. Sinnollareddy MG, Roberts MS, Lipman J, Peake SL, Roberts JA. Pharmacokinetics of piperacillin in critically ill patients with acute kidney injury receiving sustained low-efficiency diafiltration. J Antimicrob Chemother. 2018;73(6):1647-50.

87. Rhodes NJ, Grove ME, Kiel PJ, O'Donnell JN, Whited LK, Rose DT, et al. Population pharmacokinetics of cefepime in febrile neutropenia: implications for dose-dependent susceptibility and contemporary dosing regimens. Int J Antimicrob Agents. 2017;50(3):482-6.

88. Roos JF, Bulitta J, Lipman J, Kirkpatrick CM. Pharmacokinetic-pharmacodynamic rationale for cefepime dosing 
regimens in intensive care units. J Antimicrob Chemother. 2006;58(5):987-93.

89. Minichmayr IK, Roberts JA, Frey OR, Roehr AC, Kloft C, Brinkmann A. Development of a dosing nomogram for continuousinfusion meropenem in critically ill patients based on a validated population pharmacokinetic model. J Antimicrob Chemother. 2018;73(5):1330-9.

90. Pai MP, Cojutti P, Pea F. Pharmacokinetics and pharmacodynamics of continuous infusion meropenem in overweight, obese, and morbidly obese patients with stable and unstable kidney function: a step toward dose optimization for the treatment of severe gram-negative bacterial infections. Clin Pharmacokinet. 2015;54(9):933-41.

91. Jamal JA, Udy AA, Lipman J, Roberts JA. The impact of variation in renal replacement therapy settings on piperacillin, meropenem, and vancomycin drug clearance in the critically ill: an analysis of published literature and dosing regimens. Crit Care Med. 2014;42(7):1640-50.

92. Roberts JA, Paul SK, Akova M, Bassetti M, De Waele JJ, Dimopoulos G, et al. DALI: defining antibiotic levels in intensive care unit patients: are current beta-lactam antibiotic doses sufficient for critically ill patients? Clin Infect Dis. 2014;58(8):1072-83.

93. Valenza G, Seifert H, Decker-Burgard S, Laeuffer J, Morrissey I, Mutters R. Comparative activity of carbapenem testing (COMPACT) study in Germany. Int J Antimicrob Agents. 2012;39(3):255-8.

94. Imani S, Buscher H, Marriott D, Gentili S, Sandaradura I. Too much of a good thing: a retrospective study of beta-lactam concentration-toxicity relationships. J Antimicrob Chemother. 2017;72(10):2891-7.

95. Beumier M, Casu GS, Hites M, Wolff F, Cotton F, Vincent JL, et al. Elevated beta-lactam concentrations associated with neurological deterioration in ICU septic patients. Miner Anestesiol. 2015;81(5):497-506.

96. Quinton MC, Bodeau S, Kontar L, Zerbib Y, Maizel J, Slama M, et al. Neurotoxic concentration of piperacillin during continuous infusion in critically ill patients. Antimicrob Agents Chemother. 2017;61(9):6.

97. Lamoth F, Buclin T, Pascual A, et al. High cefepime plasma concentrations and neurological toxicity in febrile neutropenic patients with mild impairment of renal function. Antimicrob Agents Chemother. 2010;54(10):4360-7.

98. Pajot O, Burdet C, Couffignal C, Massias L, et al. Impact of imipenem and amikacin pharmacokinetic/pharmacodynamic parameters on microbiological outcome of Gram-negative bacilli ventilator-associated pneumonia. J Antimicrob Chemother. 2015;70(5):1487-94.

99. Kashuba AD, Nafziger AN, Drusano GL, Bertino JS. Optimizing aminoglycoside therapy for nosocomial pneumonia caused by gram-negative bacteria. Antimicrob Agents Chemother. 1999;43(3):623-9.

100. Moore RD, Lietman PS, Smith CR. Clinical response to aminoglycoside therapy: importance of the ratio of peak concentration to minimal inhibitory concentration. J Infect Dis. 1987;155(1):93-9.

101. Zelenitsky SA, Harding GK, Sun S, Ubhi K, Ariano RE. Treatment and outcome of Pseudomonas aeruginosa bacteraemia: an antibiotic pharmacodynamic analysis. J Antimicrob Chemother. 2003;52(4):668-74.

102. Nicolau DP, Freeman CD, Belliveau PP, Nightingale CH, Ross JW, Quintiliani R. Experience with a once-daily aminoglycoside program administered to 2,184 adult patients. Antimicrob Agents Chemother. 1995;39(3):650-5.

103. Rea RS, Capitano B. Optimizing use of aminoglycosides in the critically ill. Semin Respir Crit Care Med. 2007;28(6):596-603.
104. Rea RS, Capitano B, Bies R, Bigos KL, Smith R, Lee H. Suboptimal aminoglycoside dosing in critically ill patients. Ther Drug Monit. 2008;30(6):674-81.

105. Roger C, Nucci B, Louart B, Friggeri A, Knani H, et al. Impact of $30 \mathrm{mg} / \mathrm{kg}$ amikacin and $8 \mathrm{mg} / \mathrm{kg}$ gentamicin on serum concentrations in critically ill patients with severe sepsis. J Antimicrob Chemother. 2016;71(1):208-12.

106. Firsov AA, Vostrov SN, Lubenko IY, Drlica K, Portnoy YA, Zinner SH. In vitro pharmacodynamic evaluation of the mutant selection window hypothesis using four fluoroquinolones against Staphylococcus aureus. Antimicrob Agents Chemother. 2003;47(5):1604-13.

107. Tam VH, Louie A, Deziel MR, Liu WG, Drusano GL. The relationship between quinolone exposures and resistance amplification is characterized by an inverted U: a new paradigm for optimizing pharmacodynamics to counterselect resistance. Antimicrob Agents Chemother. 2007;51(2):744-7.

108. van Zanten ARH, Polderman KH, van Geijlswijk IM, van der Meer GYG, Schouten MA, Girbes ARJ. Ciprofloxacin pharmacokinetics in critically ill patients: a prospective cohort study. J Crit Care. 2008;23(3):422-30.

109. Cazaubon Y, Bourguignon L, Goutelle S, Martin O, Maire P, Ducher M. Are ciprofloxacin dosage regimens adequate for antimicrobial efficacy and prevention of resistance? Pseudomonas aeruginosa bloodstream infection in elderly patients as a simulation case study. Fundam Clin Pharmacol. 2015;29(6):615-24.

110. Haeseker M, Stolk L, Nieman F, Hoebe C, Neef C, Bruggeman $\mathrm{C}$, et al. The ciprofloxacin target AUC:MIC ratio is not reached in hospitalized patients with the recommended dosing regimens. Br J Clin Pharmacol. 2013;75(1):180-5.

111. Zavascki AP, Goldani LZ, Cao G, Superti SV, Lutz L, Barth AL, et al. Pharmacokinetics of intravenous polymyxin B in critically ill patients. Clin Infect Dis. 2008;47(10):1298-304.

112. Sandri AM, Landersdorfer CB, Jacob J, Boniatti MM, Dalarosa MG, Falci DR, et al. Population pharmacokinetics of intravenous polymyxin $b$ in critically ill patients: implications for selection of dosage regimens. Clin Infect Dis. 2013;57(4):524-31.

113. Nelson BC, Eiras DP, Gomez-Simmonds A, Loo AS, Satlin MJ, Jenkins SG, et al. Clinical outcomes associated with polymyxin $\mathrm{B}$ dose in patients with bloodstream infections due to carbapenem-resistant Gram-negative rods. Antimicrob Agents Chemother. 2015;59(11):7000-6.

114. Karaiskos I, Friberg LE, Pontikis K, Ioannidis K, Tsagkari $\mathrm{V}$, Galani L, et al. Colistin population pharmacokinetics after application of a loading dose of 9 mu colistin methanesulfonate in critically ill patients. Antimicrob Agents Chemother. 2015;59(12):7240-8.

115. Nation RL, Garonzik SM, Thamlikitkul V, et al. Dosing guidance for intravenous colistin in critically-ill patients. Clin Infect Dis. 2017;64(5):565-71.

116. Parker SL, Frantzeskaki F, Wallis SC, Diakaki C, et al. Population pharmacokinetics of fosfomycin in critically ill patients. Antimicrob Agents Chemother. 2015;59(10):6471-6.

117. Bacconi A, Richmond GS, Baroldi MA, Laffler TG, et al. Improved sensitivity for molecular detection of bacterial and Candida infections in blood. J Clin Microbiol. 2014;52(9):3164-74.

118. Drusano GL, Fregeau C, Liu W, Brown DL, Louie A. Impact of burden on granulocyte clearance of bacteria in a mouse thigh infection model. Antimicrob Agents Chemother. 2010;54(10):4368-72.

119. Drusano GL, Vanscoy B, Liu W, Fikes S, Brown D, Louie A. Saturability of granulocyte kill of Pseudomonas aeruginosa in a murine model of pneumonia. Antimicrob Agents Chemother. 2011;55(6):2693-5. 
120. Monack DM, Hultgren SJ. The complex interactions of bacterial pathogens and host defenses. Curr Opin Microbiol. 2013;16(1):1-3.

121. Maurice NM, Bedi B, Sadikot RT. Pseudomonas aeruginosa biofilms: host response and clinical implications in lung infections. Am J Respir Cell Mol Biol. 2018;58(4):428-39.

122. Chastre J, Wolff M, Fagon JY, Chevret S, Thomas F, Wermert $\mathrm{D}$, et al. Comparison of 8 vs 15 days of antibiotic therapy for ventilator-associated pneumonia in adults: a randomized trial. JAMA. 2003;290(19):2588-98.

123. Yusuf E, Van Herendael B, Verbrugghe W, et al. Emergence of antimicrobial resistance to Pseudomonas aeruginosa in the intensive care unit: association with the duration of antibiotic exposure and mode of administration. Ann Intensive Care. 2017;7(1):72.

124. Li RC, Zhu ZY. The integration of four major determinants of antibiotic action: bactericidal activity, postantibiotic effect, susceptibility, and pharmacokinetics. J Chemother. 2002;14(6):579-83.

125. Sauer K, Camper AK, Ehrlich GD, Costerton JW, Davies DG. Pseudomonas aeruginosa displays multiple phenotypes during development as a biofilm. J Bacteriol. 2002;18(4):1140-54.

126. Schembri MA, Kjaergaard K, Klemm P. Global gene expression in Escherichia coli biofilms. Mol Microbiol. 2003;48(1):253-67.

127. Denis B, Lafaurie M, Donay JL, Fontaine JP, et al. Prevalence, risk factors, and impact on clinical outcome of extended-spectrum beta-lactamase-producing Escherichia coli bacteraemia: a five-year study. Int J Infect Dis. 2015;39:1-6.

128. Vehreschild MJ, Hamprecht A, Peterson L, Schubert S, et al. A multicentre cohort study on colonization and infection with ESBL-producing Enterobacteriaceae in high-risk patients with haematological malignancies. J Antimicrob Chemother. 2014;69(12):3387-92.

129. Adam D, Zellner PR, Koeppe P, Wesch R. Phannacokinetics of ticarcillin/clavulanate in severely burned patients. J Antimicrob Chemother. 1989;24:121-9.
130. Oesterreicher Z, Minichmayr I, Sauermann R, et al. Pharmacokinetics of doripenem in plasma and epithelial lining fluid (ELF): comparison of two dosage regimens. Eur J Clin Pharmacol. 2017;73(12):1609-13.

131. Lipš M, Siller M, Strojil J, Urbánek K, Balík M, Suchánková H. Pharmacokinetics of imipenem in critically ill patients during empirical treatment of nosocomial pneumonia: a comparison of 0.5-h and 3-h infusions. Int J Antimicrob Agents. 2014;44(4):358-62.

132. Taccone FS, Laterre PF, Spapen H, Dugernier T, et al. Revisiting the loading dose of amikacin for patients with severe sepsis and septic shock. Crit Care. 2010;14(2):R53.

133. Sawchuk RJ, Zaske DE, Cipolle RJ, Wargin WA, Strate RG. Kinetic model for gentamicin dosing with the use of individual patient parameters. Clin Pharmacol Ther. 1977;21(3):362-9.

134. Lipman J, Scribante J, Gous AG, Hon H, Tshukutsoane S, The Baragwanath Ciprofloxacin Study Group. Pharmacokinetic profiles of high-dose intravenous ciprofloxacin in severe sepsis. Antimicrob Agents Chemother. 1998;42(9):2235-9.

135. Fowler RG, Degnen GE, Cox EC. Mutational specificity of a conditional Escherichia coli mutator, mutD5. Mol Gen Genet. 1974;133:179-91.

136. Zeitlinger MA, Dehghanyar P, Mayer BX, et al. Relevance of soft-tissue penetration by levofloxacin for target site bacterial killing in patients with sepsis. Antimicrob Agents Chemother. 2003;47(11):3548-53.

137. Roberts JA, Lipman J. Optimal doripenem dosing simulations in critically ill nosocomial pneumonia patients with obesity, augmented renal clearance, and decreased bacterial susceptibility. Crit Care Med. 2013;41(2):489-95.

138. Zedtwitz-Liebenstein K, Schenk P, Apfalter P, Fuhrmann V, et al. Ventilator-associated pneumonia: increased bacterial counts in bronchoalveolar lavage by using urea as an endogenous marker of dilution. Crit Care Med. 2005;33:756-9. 